OPEN ACCESS

Edited by:

Avinash Mishra,

Central Salt \& Marine Chemicals Research Institute (CSIR), India

Reviewed by:

M. Teresa Sanchez-Ballesta,

Instituto de Ciencia y Tecnología

de Alimentos y Nutrición

(ICTAN-CSIC), Spain

Jose Luis Reyes,

Universidad Nacional Autónoma

de México, Mexico

Steffen P. Graether,

University of Guelph, Canada

${ }^{*}$ Correspondence:

Sudipta Ray

srbot@caluniv.ac.in

Specialty section:

This article was submitted to

Plant Abiotic Stress,

a section of the journal

Frontiers in Plant Science

Received: 31 October 2017

Accepted: 24 January 2018

Published: 14 February 2018

Citation:

Halder T, Upadhyaya G, Basak C,

Das A, Chakraborty C and Ray S

(2018) Dehydrins Impart Protection against Oxidative Stress in Transgenic

Tobacco Plants.

Front. Plant Sci. 9:136.

doi: 10.3389/fpls.2018.00136

\title{
Dehydrins Impart Protection against Oxidative Stress in Transgenic Tobacco Plants
}

\section{Tanmoy Halder, Gouranga Upadhyaya, Chandra Basak, Arup Das, Chandrima Chakraborty and Sudipta Ray*}

Plant Functional Genomics Laboratory, Centre of Advanced Study, Department of Botany, University of Calcutta, Kolkata, India

Environmental stresses generate reactive oxygen species (ROS) which might be detrimental to the plants when produced in an uncontrolled way. However, the plants ameliorate such stresses by synthesizing antioxidants and enzymes responsible for the dismutation of ROS. Additionally, the dehydrins were also able to protect the inactivation of the enzyme lactate dehydrogenase against hydroxyl radicals $(\mathrm{OH})$ generated during Fenton's reaction. SbDhn1 and SbDhn2 overexpressing transgenic tobacco plants were able to protect against oxidative damage. Transgenic tobacco lines showed better photosynthetic efficiency along with high chlorophyll content, soluble sugar and proline. However, the malonyl dialdehyde (MDA) content was significantly lower in transgenic lines. Experimental evidence demonstrates the protective effect of dehydrins on electron transport chain in isolated chloroplast upon methyl viologen (MV) treatment. The transgenic tobacco plants showed significantly lower superoxide radical generation $\left(\mathrm{O}_{2}^{--}\right)$upon $\mathrm{MV}$ treatment. The accumulation of the $\mathrm{H}_{2} \mathrm{O}_{2}$ was also lower in the transgenic plants. Furthermore, in the transgenic plants the expression of ROS scavenging enzymes was higher compared to non-transformed (NT) or vector transformed (VT) plants. Taken together these data, during oxidative stress dehydrins function by scavenging the $\left(\mathrm{O}_{2}^{-}\right)$directly and also by rendering protection to the enzymes responsible for the dismutation of $\left(\mathrm{O}_{2}^{-}\right)$thereby significantly reducing the amount of hydrogen peroxides formed. Increase in proline content along with other antioxidants might also play a significant role in stress amelioration. Dehydrins thus function co-operatively with other protective mechanisms under oxidative stress conditions rendering protection in stress environment.

Keywords: dehydrin, oxidative stress, methyl viologen, electron transport chain, protoplast

Abbreviations: APX, ascorbate peroxidase; BAP, 6-benzylaminopurine; BSA, bovine serum albumin; CAT, catalase; CIB, chloroplast isolation buffer; DAB, 3,3'-diaminobenzidine; DCPIP, 2,6-dichlorophenolindophenol; DHE, dihydroethidium; $\mathrm{Fv} / \mathrm{Fm}$, maximum quantum yield of PSII; $\mathrm{H}_{2} \mathrm{O}_{2}$, hydrogen peroxide; $\mathrm{LDH}$, lactate dehydrogenase; LEA, late embryogenesis abundant; MDA, malonyl dialdehyde; MS, Murashige and Skoog; MV, methyl viologen; NAA, naphthalene acetic acid; NT, non-transformed; ${ }^{1} \mathrm{O}_{2}$, singlet oxygen; $\mathrm{O}_{2}^{--}$, superoxide radical; $\mathrm{OH}$, hydroxyl radical; PCR, polymerase chain reaction; POX, peroxidase; ROS, reactive oxygen species; SDS-PAGE, sodium sodecyl sulfate-polyacrylamide gel electrophoresis; SOD, superoxide dismutase; TBA, thiobarbituric acid; TCA, trichloroacetic acid; VT, vector transformed. 


\section{INTRODUCTION}

Several environmental situations such as drought, salinity, temperature variation are the major stress factors, which hamper plant growth throughout their life cycle. The primary stress factors like drought, salinity, high temperature may further culminate into oxidative stress causing severe cellular damage (Foyer and Mullineaux, 1994; Van Breusegem et al., 1999; Mittler, 2002). The ROS generated in cells produce oxidative stress due to the formation of ${ }^{1} \mathrm{O}_{2}, \mathrm{O}_{2}^{-}, \mathrm{H}_{2} \mathrm{O}_{2}$, and the hydroxyl radicals $\left(\mathrm{HO}^{\circ}\right)$. However, tolerance to such damaging conditions may be achieved by effective scavenging mechanisms for the excessively accumulated ROS.

The cellular protection and damage repair mechanism work together to increase the stability of the proteins and biomolecules and preventing protein aggregation. Proteins stability and prevention of aggregation can be achieved by accumulating molecular chaperones as well as highly hydrophilic proteins like dehydrins, a group II LEA proteins (Konrad and Bar-Zvi, 2008; Halder et al., 2016). In general, all dehydrins contain at least a copy of $\mathrm{K}$ segment (EKKGIMDKIKEKLPG) usually present in the $\mathrm{C}$-terminus of the protein. Along with the $\mathrm{K}$ segment, dehydrin may possess some other conserved motifs viz. Y segment (T/VDEYGNP), S segment (a motif rich in Ser residues) and randomly present $\Phi$-segment (Close, 1997). The number and distribution pattern of the $\mathrm{K}, \mathrm{Y}$, and $\mathrm{S}$ motifs define the different sub-classes of dehydrins viz. $K_{n} S, K_{n}$, $\mathrm{Y}_{\mathrm{n}} \mathrm{SK}_{\mathrm{n}}, \mathrm{Y}_{\mathrm{n}} \mathrm{K}_{\mathrm{n}}, \mathrm{SK}_{\mathrm{n}}$. Numerous studies have been documented suggesting different molecular functions of the protein. These include cryoprotection (Agarwal et al., 2017), protecting cell membrane from lipid peroxidation (LPO), scavenging ROS and metal binding activity. Radical scavenging activity and oxidative modification of CuCOR19 and AtHIRD11 were earlier reported by Hara et al. (2004, 2013). Earlier report by Hara et al. (2004) showed that CuCOR19 (a $\mathrm{K}_{\mathrm{n}} \mathrm{S}$ type dehydrin from Citrus) was capable of scavenging the hydroxyl radical generated by the $\mathrm{Fe}^{2++} / \mathrm{H}_{2} \mathrm{O}_{2}$ system and peroxyl radical generated from 2, 2 -azobis (2-amidinopropane). Earlier reports also suggested the protective role of dehydrins against oxidative damage caused by ROS and metal ions (Zhang et al., 2006). Earlier report of a $\mathrm{K}_{\mathrm{n}} \mathrm{S}$ type dehydrin was shown to bind metal ions (Hara et al., 2005). Sequestration of the metal ions inhibits the production of hydroxyl radical $\left(\mathrm{OH}^{\circ}\right)$ through Fenton's reaction (GenaroMattos et al., 2015). The hydroxyl radicals are highly deleterious to cellular components; therefore, their levels are kept at a minimal level as compared to superoxides and $\mathrm{H}_{2} \mathrm{O}_{2}$. Enhanced tolerance toward oxidative as well as salt stress was achieved by over-expressing MusaWRKY71 in banana plants leading to better photosynthetic efficiency $(F \mathrm{v} / F \mathrm{~m})$ and lower membrane damage (Shekhawat and Ganapathi, 2013). Dehydrin can protect the cell membranes against LPO during oxidative stress condition (Hara et al., 2003). SK $\mathrm{n}$ type dehydrins (Danyluk et al., 1998; Yang et al., 2014) were found near the plasma membrane. The in vitro association of dehydrins to membranes has been shown by several researchers (Ismail et al., 1999; Hara et al., 2001; Koag et al., 2003, 2009; Soulages et al., 2003). Their work suggested that dehydrins gain $\alpha$-helical structure in the presence of negatively charged liposomes and micelles. It was shown previously that the $\mathrm{K}$-segment is responsible for binding to membranes (Koag et al., 2009). It has been proposed by Eriksson et al. (2011) that the histidine residues located on either side of the K-segments in LTI30 help to modulate membrane binding. However, all dehydrin K-segments are not flanked by His residues and even the $\mathrm{K}$-peptide alone has been shown to bind vesicles (Koag et al., 2009) which clearly indicate that occurrence of these histidine residues near the K-segments are not critical for membrane binding activity for other dehydrins. Depending on the lipid compositions mimicking the plasma membrane, mitochondrial membrane and chloroplast membrane, Thellungiella salsuginea dehydrin 1 (TsDHN-1) showed difference in type and amount of structural change (Rahman et al., 2010, 2013). The membranes mimicking the chloroplast are considerably different from others, as they primarily consist of the galactolipids monogalactosyldiacylglycerol (MGDG) and digalactosyldiacylglycerol (DGDG), which are neutral. The binding of dehydrins to plant outer and organellar membranes should therefore impart protection to the plants under stress conditions. The major sources of ROS are organelles such as chloroplasts, mitochondria or microbodies which have a highly oxidizing metabolic activity or having an intense rate of electron flow (Apel and Hirt, 2004). The chloroplast and peroxisomes are the two major organelles contributing to the oxidative load in plant cells during environmental stress. In order to ward off the oxidative damage in plants, a number of mechanisms orchestra together to handle the oxidative stress conditions. This is generally achieved by production of antioxidants and radical scavengers along with an increase in enzymes responding to dismutation of free radicals. The imbalance between the production of ROS and its scavenging mechanisms may initiate uncontrolled oxidative cascades.

The enhancement of ROS, under stressed condition, acts as an alarm bell for triggering the defense response pathway genes where $\mathrm{H}_{2} \mathrm{O}_{2}$ acts as a secondary messenger in the signal transduction pathway (Orozco-Cárdenas et al., 2001). A versatile and cooperative antioxidant system in the cell keeps the enhanced ROS production under tight control. An array of enzymatic and non-enzymatic antioxidants functions as an efficient system to keep the ROS level under control. Among the ROS the superoxides are primarily produced in large amount upon encountering oxidative stress (Apel and Hirt, 2004). SOD serves as a major scavenging enzyme in dismutating superoxides to $\mathrm{O}_{2}$ and $\mathrm{H}_{2} \mathrm{O}_{2}$; however, this only converts the ROS from its one form to other. The $\mathrm{H}_{2} \mathrm{O}_{2}$ thus produced in this reaction can attack the thiol proteins. CAT and APX are the other major enzymatic proteins that can convert the $\mathrm{H}_{2} \mathrm{O}_{2}$ into water and oxygen. Previous reports also showed an increase in SOD, POX, and CAT activity in overexpressed dehydrin plants which showed enhanced tolerance under oxidative stress conditions (Liu et al., 2017).

Here in this current study two dehydrin genes, SbDhn1 (Accession no. KT865881) and SbDhn2 (Accession no. KT780443) were analyzed under oxidative stress conditions. SbDhn1 (YSK 2 type) and SbDhn2 (SK 3 type) were previously isolated and characterized from Sorghum bicolor (Halder et al., 
2016, 2017). Previously we reported that SbDhn1 was found to play a protective role under high temperature and osmotic stress when over expressed in tobacco plants. The ease of Agrobacterium mediated transformation, and optimized tissue culture media make it suitable for use as a model plant. Previous data also showed that SbDhn2 possessed metal binding as well as radical scavenging activity (Halder et al., 2016). Here, we compare the scavenging activity between the two dehydrins (SbDHN1 and SbDHN2). The metal sequestration activity of some dehydrins could prevent the $(\mathrm{OH} \cdot)$ generation by sequestering the metal ions required in Fenton's reaction. In order to elucidate the role of dehydrin genes during oxidative stress conditions, transgenic tobacco plants overexpressing dehydrins were subjected to MV. The transgenic lines showed better photosynthetic efficiency under oxidative stress conditions. Here, we provide direct evidence for the protection rendered by dehydrins during oxidative stress conditions to isolated chloroplast when added externally and also when synthesized in planta. The membrane binding activity of the dehydrins might be responsible for such protection. Dehydrins could protect the plants directly by scavenging the ROS or rendering overall protective effect to the enzymes responsible for dismutation of free radicals. Thus overexpression of dehydrin genes in transgenic tobacco plants showed better physiological conditions as compared to that of NT and VT plants.

\section{MATERIALS AND METHODS}

\section{Cloning, Expression, and Purification of SbDhn1 and SbDhn2}

The cloning, expression, and purification of the two proteins $S b D h n 1$ and $S b D h n 2$ were carried out as described previously by Halder et al. $(2016,2017)$. The dehydrin genes were amplified by gene specific primers (Supplementary Table S1) from Sorghum bicolor and cloned in pGEMT easy vector. The CDS was subcloned in bacterial expression vector at NdeI and XhoI sites. The expression was induced by $1 \mathrm{mM}$ IPTG at $37^{\circ} \mathrm{C}$ at $180 \mathrm{rpm}$ in Rosetta (DE3) pLysS cells. The expressed recombinant protein was purified by affinity column chromatography with the help of His tagged and GST tagged fusion protein, which was subsequently digested by Factor Xa. After affinity purification, the purified protein was confirmed by immunoblotting with anti-His antibody and HRP conjugated secondary antibody.

\section{Generation of SbDhn1 and SbDhn2 Overexpressing Tobacco Lines}

The SbDhn1 transformed plants were raised as described previously by Halder et al. (2017). The SbDhn2 gene was placed under the control of CaMV35S promoter and cloned in plant expression vector. The chimeric plant expression cassette was then mobilized in Agrobacterium tumefaciens strain LBA4404 by freeze-thaw method. Agrobacterium-mediated tobacco leaf disc (Nicotiana tabacum; variety SR) transformation was carried out as described by Horsch et al. (1985). The putative transgenic plants were analyzed by PCR amplification of dehydrin (SbDhn1 or SbDhn2) and hygromycin resistance genes $(h p t)$. Details of the oligonucleotide primers used in this study are given in Supplementary Table S1.

\section{Effect of Dehydrins on LDH Activity under Oxidative Stress}

In order to evaluate the protective activity of the SbDHN1 and SbDHN2 protein under oxidative stress condition, $\mathrm{LDH}$ protection assay was performed as described previously by Halder et al. (2016). The effect of free radicals on $\mathrm{LDH}$ was determined by incubating $0.05 \mathrm{U}$ of $\mathrm{LDH}$ with $0.1 \mathrm{mM} \mathrm{FeSO}_{4}$ and $1 \mathrm{mM} \mathrm{H}_{2} \mathrm{O}_{2}$ in absence or presence of SbDHN1 or SbDHN2 or BSA at different concentrations ranging from $200 \mathrm{ng} / \mu \mathrm{l}$ to $1 \mu \mathrm{g} / \mu \mathrm{l}$, for $10 \mathrm{~min}$ at $25^{\circ} \mathrm{C}$. Following incubation, $\mathrm{LDH}$ activity was measured in $1 \mathrm{ml}$ of reaction mix containing $1.1 \mathrm{mM}$ pyruvic acid and $0.13 \mathrm{mM}$ $\mathrm{NADH}$. Oxidation of $\mathrm{NADH}$ was calculated from the reading obtained at $\mathrm{A}_{340}$ for $5 \mathrm{~min}$ in a spectrophotometer (Jasco, V$730)$ during the linear reaction rate. $N$-Acetyl-L-cysteine (50 $\mu \mathrm{M})$ a known radical scavenger was used as a positive control to compare the radical scavenging activity of the dehydrin proteins. The effect of either $\mathrm{FeSO}_{4}$ or $\mathrm{H}_{2} \mathrm{O}_{2}$ alone on the $\mathrm{LDH}$ activity was also evaluated. In order to do so same amount of $\mathrm{LDH}$ was incubated with different concentration of $\mathrm{FeSO}_{4}$ ranging from $0.01 \mathrm{mM}$ to $0.25 \mathrm{mM}$ or different concentration of $\mathrm{H}_{2} \mathrm{O}_{2}$ ranging from $0.1 \mathrm{mM}$ to $2.5 \mathrm{mM}$ for $10 \mathrm{~min}$ at $25^{\circ} \mathrm{C}$. Following incubation, the $\mathrm{LDH}$ activity was measured as mentioned above. The protective effect of dehydrins on the $\mathrm{LDH}$ in presence of either $\mathrm{FeSO}_{4}$ or $\mathrm{H}_{2} \mathrm{O}_{2}$ was also evaluated. Same amount of $\mathrm{LDH}$ was incubated with either $0.1 \mathrm{mM} \mathrm{FeSO}_{4}$ or $1 \mathrm{mM} \mathrm{H}_{2} \mathrm{O}_{2}$ in presence or absent of $1 \mu \mathrm{g} / \mu \mathrm{l}$ of SbDHN1or SbDHN2 or BSA. Following incubation, the LDH activity was measured.

\section{Effect of Oxidative Stress on Transgenic Plants}

For evaluating the effect of the MV on transgenic plants, leaf disc assay was carried out. Leaf discs (1 cm diameter) were punched from the third and fourth fully expanded leaves of transgenic plants (SbDhn1 or SbDhn2 lines), NT, as well as VT lines. Leaf discs were collected from three different lines for $S b D h n 1$ or SbDhn2 plants and the assay was carried out in triplicate. The leaf discs were then placed in half MS media (Murashige and Skoog, 1962) containing $20 \mu \mathrm{M}$ MV with the abaxial side of the leaf facing the media. The leaf discs were incubated for 5 days under continuous illumination at $22^{\circ} \mathrm{C}$ temperature and $70 \%$ relative humidity. The leaf discs from a NT plant were placed in half MS medium without MV which served as a control. Photographs were taken at 0 day and 5 days after incubation.

In order to evaluate the effect of $\mathrm{MV}$ on whole plants, transgenic plants overexpressing dehydrin genes (SbDhn1: Lines and SbDhn2: Lines), NT and VT plants were grown under normal culture conditions $\left(25^{\circ} \mathrm{C}\right.$ temperature and $70 \%$ relative humidity with $16 \mathrm{~h}$ photoperiod) for 21 days. The plants were then transferred to MS basal media (Murashige and Skoog, 1962) containing $50 \mu \mathrm{M} \mathrm{MV}$ and incubated for 5 days under 
continuous illumination at $22^{\circ} \mathrm{C}$ temperature and $70 \%$ relative humidity. The plants were photographed before and after the stress treatment. The whole experiment was repeated three times.

\section{Estimation of Proline Content}

Proline content was estimated by using the method described by Ábrahám et al. (2010). Acidic ninhydrin reagent was used to estimate the total proline content of the plants. The reagent was prepared by dissolving $2.5 \mathrm{~g}$ of ninhydrin in $100 \mathrm{ml}$ of the solution containing glacial acetic acid: distilled water: $85 \%$ orthophosphoric acid at a ratio of 6:3:1. One hundred milligrams of leaf samples were homogenized in $1 \mathrm{ml}$ of $3 \%(\mathrm{w} / \mathrm{v})$ aqueous sulfosalicylic acid solution and centrifuged at $12,000 \times g$ for $15 \mathrm{~min}$ at $4^{\circ} \mathrm{C}$. Following incubation, $1 \mathrm{ml}$ of supernatant was collected and mixed with equal volume of glacial acetic acid and ninhydrin reagent and kept in a boiling water bath for $1 \mathrm{~h}$. The reaction was stopped by incubating the reaction in a water bath at room temperature $\left(21^{\circ} \mathrm{C}\right)$ for $5 \mathrm{~min}$. The absorbance was measured immediately at $546 \mathrm{~nm}$ using Jasco V730 IRM spectrophotometer. Total proline content was estimated by using a proline standard curve as a reference and expressed in $\mathrm{mg} / \mathrm{g}$ fresh tissue.

\section{Determination of the Malonyldialdehyde (MDA) Content}

Malonyl dialdehyde content was estimated as per the method of Baryla et al. (2000). For quantification of MDA content in stressed and unstressed transgenic, NT, and VT tobacco plants, approximately, $100 \mathrm{mg}$ of leaf material was extracted in $1 \mathrm{ml}$ $0.1 \%(\mathrm{w} / \mathrm{v})$ TCA solution. The homogenates were centrifuged at $12,000 \times g$ for $15 \mathrm{~min}$ at $4^{\circ} \mathrm{C}$. Five hundred microliters of supernatant was then mixed with $1 \mathrm{ml} 0.5 \%$ TBA solution (500 mg TBA dissolved in $100 \mathrm{ml}$ of $20 \%$ TCA). Then the reaction mixture was placed in a boiling water bath for $1 \mathrm{~h}$ and immediately kept on ice for $5 \mathrm{~min}$. The absorption of the samples was measured at $532 \mathrm{~nm}$, after centrifugation at $10,000 \times g$ for $10 \mathrm{~min}$. The data were calculated from the extinction coefficient of MDA (155 $\left.\mathrm{mM}^{-1} \mathrm{~cm}^{-1}\right)$ after subtracting the value of nonspecific absorption at $600 \mathrm{~nm}$.

\section{Total Chlorophyll Content}

Total chlorophyll content was measured spectrophotometrically according to Arnon (1949). Briefly, $100 \mathrm{mg}$ of leaf were crushed in $2 \mathrm{ml}$ of $80 \%$ acetone followed by centrifugation at $10,000 \times g$ for $10 \mathrm{~min}$ at $25^{\circ} \mathrm{C}$. The clear supernatant was collected and absorbance at $645 \mathrm{~nm}$ and $663 \mathrm{~nm}$ were recorded. The total chlorophyll content was calculated using the formula given below:

$$
\text { Total chlorophyll }=\frac{[20.2(\mathrm{D} 645)+8.02(\mathrm{D} 663)] \mathrm{V}}{(1000) \mathrm{W}}
$$

[Where, D, optical density value; $\mathrm{V}$, final volume of $80 \%$ alkaline acetone; W, fresh weight in grams of tissue extract]. The total chlorophyll content was estimated in the term of $\mathrm{mg} / \mathrm{g}$ of fresh tissue.

\section{Estimation of Total Soluble Sugar}

Total soluble sugar content was estimated according to Irigoyen et al. (1992) with some minor modifications. Leaf samples (100 mg) were extracted in $1 \mathrm{ml}$ of $95 \%$ ethanol followed by centrifugation at $13,000 \times g$ for $10 \mathrm{~min}$ at $25^{\circ} \mathrm{C}$. After centrifugation, $100 \mu \mathrm{l}$ supernatant was mixed with $1 \mathrm{ml}$ anthrone solution (15 mg anthrone dissolved in $10 \mathrm{ml}$ of $72 \% \mathrm{H}_{2} \mathrm{SO}_{4}$ ), and incubated for $10 \mathrm{~min}$ in water bath at $90-95^{\circ} \mathrm{C}$. Following incubation, the samples were cooled and the absorbance was measured at $625 \mathrm{~nm}$ using Jasco V730 IRM spectrophotometer. Total soluble sugar was estimated by using glucose as a standard reference and expressed in $\mathrm{mg} / \mathrm{g}$ fresh weight of leaves.

\section{Measurement of Photosynthetic Efficiency}

The photosynthetic efficiency of stressed (SbDhn1, SbDhn2, NT and VT plants) as well as unstressed NT plants were analyzed using a portable Chlorophyll Fluorimeter (Handy PEA, Hansatech Instruments, Ltd., Norfolk, United Kingdom) by estimating chlorophyll fluorescence. The distal extremities of the central vein of the leaf blade of the third and fifth leaves (counted from the top) were measured. Firstly, the sample area to be analyzed was covered by leaf clips for dark adaptation. Three leaf clips were attached to the leaf to maintain a particular area under the dark condition for $30 \mathrm{~min}$ so that the reaction centers acquire the open condition (oxidized Qa) (Bolhar-Nordenkampf et al., 1989). After dark adjustment, illumination was supplied by an array of six LEDs emitting red light, optically filtered to a peak wavelength of $650 \mathrm{~nm}$ at a maximum intensity of up to 3,500 $\mu \mathrm{mol} \mathrm{m} \mathrm{m}^{-2} \mathrm{~s}^{-1}$ on the surface of leaf (4 $\mathrm{mm}$ in diameter) placed in the clips. Leaf model was generated from JIP-test parameters by using the Biolyzer software (Discoverer: Ronald Maldonado Rodriguez) and the following variables were measured and calculated; (1) $\mathrm{ABS} / \mathrm{CS}_{\mathrm{m}}$ ratio: the total number of photons absorbed by an excited PS II cross section. (2) $\mathrm{TR}_{0} / \mathrm{CS}_{\mathrm{m}}$ : the maximal trapping rate of an exciton that will lead to $\mathrm{Q}$ a reduction measured over a cross-section of active and inactive RCs (reaction centers), (3) $\mathrm{DI}_{0} / \mathrm{CS}_{\mathrm{m}}$ : The dissipation of untrapped excitation energy per excited cross-section. Dissipation occurs as heat, fluorescence and energy transfer to other systems. It is influenced by the ratio of active/inactive RCs, (4) Electron transport in a PS II cross section $\left(\mathrm{ET}_{0} / \mathrm{CS}_{\mathrm{m}}\right)$ : deals with the reoxidation of reduced Q $\mathrm{Q}$ via electron transport over a crosssection of active and inactive RCs (Force et al., 2003).

\section{Isolation of Chloroplast and Electron Transport Chain Assay}

Intact chloroplasts were isolated from tobacco plants as described by Nakano and Asada (1981) with some minor modifications. Briefly, $50 \mathrm{mM}$ phosphate buffer $\mathrm{pH} 7.0$, containing $0.4 \mathrm{M}$ sucrose and $10 \mathrm{mM} \mathrm{KCl}$ was used as CIB. Plant material was homogenized by using mixer grinder; filtered through $50 \mu \mathrm{m}$ mesh cloth and the filtrate was centrifuged at $200 \times g$ for 5 min at room temperature. The supernatant was collected and again centrifuged at $1,500 \times g$ at room temperature for $7 \mathrm{~min}$ to pellet down the chloroplasts. The supernatant was discarded and 
the pellet containing the chloroplast was redissolved in CIB. Intact chloroplasts were then purified through sucrose gradient. The number of intact chloroplasts was determined by using haemocytometer and an equal amount of chloroplast was used for electron transport assay.

The isolated chloroplasts were suspended in assay buffer containing (50 $\mathrm{mM}$ phosphate buffer $\mathrm{pH} 7.0,0.05 \mathrm{M} \mathrm{KCl}$ ) in presence or absence of SbDHN1 or SbDHN2 protein at a concentration of $2 \mu \mathrm{g} / \mathrm{ml}$. One millimolar $\mathrm{MV}$ was used as an electron acceptor and generation of oxidative stress and $0.05 \mu \mathrm{g} / \mathrm{ml}$ DCPIP was used as a reducing agent. The samples were illuminated for $5 \mathrm{~min}$ and absorbance was measured at $604 \mathrm{~nm}$. The reaction mixture without any protein was used as a negative control and with $2 \mu \mathrm{g} / \mathrm{ml}$ of BSA was used as a positive control. The $100 \%$ activity was the activity shown by the isolated chloroplast in absence of MV. The data represented here shows the percentage of protection of the protein against oxidative stress.

The chloroplasts were also isolated from NT, VT, SbDhn1, and $S b D h n 2$ transformed lines. The experimental setup was same as described previously. In these experiments, no protein was added externally. The over expressed lines of $S b D h n 1$ and $S b D h n 2$ were used to measure the level of protection imparted by the dehydrin proteins during oxidative stress. The chloroplasts isolated from NT plant without MV served as a control in this experiment. Absorbance was measured at $604 \mathrm{~nm}$ after incubating for $5 \mathrm{~min}$ under light condition.

\section{Superoxide Radical Generation in Tobacco Protoplast}

Protoplasts were isolated from leaf tissue of transgenic, NT and VT plants according to Yoo et al. (2007) with few modifications. One hundred milligrams of leaf samples were cut into 0.5-1 sq.mm leaf strips excluding the midrib using a sharp blade without crushing the tissue at the cutting edges. Leaf strips were digested with freshly prepared enzyme solution $(20 \mathrm{mM}$ MES, pH 5.7 containing $0.5 \%(\mathrm{w} / \mathrm{v})$ cellulase 'onozuka' R10, $0.17 \%(\mathrm{w} / \mathrm{v})$ macerozyme 'onozuka' R10, $0.4 \mathrm{M}$ mannitol and $20 \mathrm{mM} \mathrm{KCl}, 10 \mathrm{mM} \mathrm{CaCl}_{2}$, and $0.1 \% \mathrm{BSA}$ ). The digestion was carried out in dark for $12 \mathrm{~h}$ at room temperature with mild shaking. Protoplast solution was then diluted with an equal volume of wash solution (2 mM MES pH 5.7 containing $154 \mathrm{mM} \mathrm{NaCl}, 125 \mathrm{mM} \mathrm{CaCl}_{2}$, and $5 \mathrm{mM} \mathrm{KCl}$ ) and filtered through a $100 \mu \mathrm{m}$ nylon mesh to remove undigested tissue. Protoplasts were then centrifuged at $100 \times g$ at room temperature for $2 \mathrm{~min}$ and the supernatant was removed. Protoplasts were washed twice with wash solution and finally dissolved in 1X PBS ( $\mathrm{pH} 7.4$ ) supplemented with $7.2 \%$ mannitol for further use.

For evaluating the superoxide production in isolated protoplasts from NT, VT, and transformed plants under oxidative stress condition, $100 \mu \mathrm{l}$ aliquots were treated with $\mathrm{MV}$ at a final concentration of $10 \mathrm{mM}$ and incubated for $15 \mathrm{~min}$ in presence of light. Staining was done with DHE (Abcam ab145360) in dark and fluorescence micrographs were taken using fluorescence microscope with excitation maxima
$392 \mathrm{~nm}$ and emission maxima $410 \mathrm{~nm}$. The fluorescence was also recorded in a spectrofluorimeter (HITACHI Fluorescence Spectrophotometer F-7000) at $\lambda_{\mathrm{ex}}=392 \mathrm{~nm}$ and $\lambda_{\mathrm{em}}=410 \mathrm{~nm}$ with a slit width of $1 \mathrm{~nm}$, at $25^{\circ} \mathrm{C}$.

Superoxide production in the transgenic, NT and VT plants was also observed when whole plants were subjected to oxidative stress treatment. Protoplasts were isolated from leaves of transgenic, NT and VT plants which were subjected to $50 \mu \mathrm{M}$ MV stress for 5 days and stained with DHE and photographed as described previously.

\section{3, 3'-Diaminobenzidine (DAB) Staining of Tobacco Plants}

Staining of tobacco leaves from SbDhn1, SbDhn2, VT and NT plants was done according to Daudi and O'Brien (2012). Fifty milligrams of DAB was dissolved in $47.5 \mathrm{ml}$ of sterile $\mathrm{H}_{2} \mathrm{O}$, the $\mathrm{pH}$ was adjusted to 3.0 by using $0.2 \mathrm{M} \mathrm{HCl}$. $0.05 \% \mathrm{v} / \mathrm{v}$ Tween-20 and $5 \% 200 \mathrm{mM} \mathrm{Na}_{2} \mathrm{HPO}_{4}$ were added to make a total volume of $50 \mathrm{ml}$. Second fully expanded leaves of NT, VT and SbDhn1 and $S b D h n 2$ transgenic plant after 5 days of MV treatment were dipped in $\mathrm{DAB}$ solution and placed on a shaker for 4-5 h at 90-100 rpm shaking speed at the dark condition. After incubation, the DAB buffer was replaced with bleaching solution (ethanol:glycerol:acetic acid in a ratio of $3: 1: 1$ ) and placed in a water bath $\left(90^{\circ} \mathrm{C}\right)$ for $15 \mathrm{~min}$. Bleaching solution was changed twice and after cooling, the leaves were photographed.

\section{Enzyme Assay for SOD, POX, APX, and CAT}

The activity of SOD was measured as described by Liang et al. (2011). Approximately $100 \mathrm{mg}$ of leaf tissue from stressed and unstressed plants (SbDhn1, SbDhn2, VT and NT) were homogenized with $50 \mathrm{mM}$ sodium phosphate buffer $\mathrm{pH} 6.8$ in a cold condition. The extract was centrifuged at $12,000 \times g$ at $4^{\circ} \mathrm{C}$ for $10 \mathrm{~min}$ and the supernatant was collected. The reaction mixture was prepared by addition of $100 \mu \mathrm{l}$ of the extracts to $13 \mathrm{mM}$ methionine, $75 \mu \mathrm{M}$ nitroblue tetrazolium and 0.1 $\mu \mathrm{M}$ disodium ethylenediamine tetraacetate in $50 \mathrm{mM}$ potassium phosphate buffer ( $\mathrm{pH}$ 7.8). The reaction was initiated under 4000 Lx candescent lamp by the addition of riboflavin $(1.3 \mu \mathrm{M})$ to the mixture. The rate of absorbance was recorded at $560 \mathrm{~nm}$ for $30 \mathrm{~min}$. One enzyme unit (U) was defined as the amount of enzyme required for inhibition of $50 \%$ NBT.

Specific activity of enzyme POX was carried out by using the method of Malik and Singh (1980) with some modification. Crude POX extracts were prepared by grinding $100 \mathrm{mg}$ of leaf tissue from stressed as well as unstressed plants (SbDhn1, SbDhn2, VT and NT) in $1 \mathrm{ml}$ of $100 \mathrm{mM}$ phosphate buffer $\mathrm{pH} 7.0$ followed by centrifugation at $12,000 \times g$ at $4^{\circ} \mathrm{C}$ for $10 \mathrm{~min}$. Reaction mixture was prepared by using $0.1 \mathrm{ml}$ enzyme extract, $900 \mu \mathrm{l}$ of the buffer solution containing $20 \mathrm{mM} 0.05 \mathrm{ml}$ guaiacol solution and $0.03 \mathrm{ml} \mathrm{H}_{2} \mathrm{O}_{2}(0.042 \%=12.3 \mathrm{mM})$. The time required for the optical density to be increased by $0.1(\Delta \mathrm{t})$ was recorded at $436 \mathrm{~nm}$ and the enzyme activity was then calculated using the formula, enzyme units $g^{-1} \mathrm{f}$ $\mathrm{wt}=[500 / \Delta \mathrm{t}] \times[1 / 1000] \times[\mathrm{TV} / \mathrm{VU}] \times[1 / \mathrm{f} \mathrm{wt}] ; \Delta \mathrm{t}$, time 
change in minute; TV, total volume of the extract $(\mathrm{ml})$; VU, volume used $(\mathrm{ml})$; $\mathrm{f}$ wt, weight of the fresh leaf tissue $(\mathrm{g})$. The enzyme activity was expressed at $\mathrm{U} / \mathrm{mg}$ protein.

Ascorbate peroxidase assay was carried out according to the method of Nakano and Asada (1981). Leaf tissues were collected from stressed and unstressed plants of SbDhn1, SbDhn2, VT and NT plants. They were crushed in $50 \mathrm{mM}$ potassium phosphate buffer ( $\mathrm{pH} 7.2$ ) containing $1 \mathrm{mM}$ ascorbate. Extracts were centrifuged at $12,000 \times g$ for $10 \mathrm{~min}$ at $4^{\circ} \mathrm{C}$ and the supernatant was collected. The reaction mixture was prepared by addition of $100 \mu \mathrm{l}$ of extract in $1 \mathrm{ml}$ of extraction buffer containing $0.5 \mathrm{mM}$ ascorbic acid, $0.1 \mathrm{mM}$ EDTA and $0.1 \mathrm{mM} \mathrm{H}_{2} \mathrm{O}_{2}$. The reaction was carried out for $5 \mathrm{~min}$ at $25^{\circ} \mathrm{C}$. Oxidation of ascorbic acid was examined by decrease in absorbance at $290 \mathrm{~nm}$. One unit of APX was referred as the amount of enzyme oxidizing $1 \mu$ mole of ascorbic acid per minute. The enzyme activity was expressed at $\mathrm{U} / \mathrm{mg}$ protein.

Catalase activity was determined spectrophotometrically following the method of Cakmak and Horst (1991). One hundred milligrams of leaf tissue was collected from transgenic plants (SbDhn1, SbDhn2), VT and NT plants subjected to MV stress and also from unstressed condition. The samples were homogenized with liquid nitrogen to a fine powder. The crushed samples were then suspended in $1 \mathrm{ml}$ of $50 \mathrm{mM}$ sodium phosphate buffer, pH-7.0. The extract was centrifuged at $12000 \times g$ at $4^{\circ} \mathrm{C}$ for $10 \mathrm{~min}$. The reaction mixture was prepared by mixing $100 \mu \mathrm{l}$ of the enzyme extract and $50 \mu \mathrm{l}$ of $\mathrm{H}_{2} \mathrm{O}_{2}(0.3 \%)$ and volume was made up to $1 \mathrm{ml}$ by addition of phosphate buffer. The decrease in absorbance was recorded through time course measurement for $3 \mathrm{~min}$ at a wavelength of 240 nm by Jasco V730 IRM spectrophotometer. CAT activity was expressed as $\mathrm{U} / \mathrm{mg}$ of protein using the molar extinction coefficient $\epsilon=43.1 \mathrm{M}^{-1} \mathrm{~cm}^{-1}$.

\section{qRT-PCR Analysis for ROS Scavenging Enzymes during Oxidative Stress}

The transcripts for the genes coding for ROS scavenging enzymes like SOD (XM_016612374.1), POX (D11396.1), APX (U15933.1), and CAT (U07627.1) were analyzed in transgenic tobacco plants under oxidative stress condition. Quantitative Real-time PCR (qRT-PCR) analysis was carried out with actin gene serving as an internal control for normalization. The primer sequences used for the real-time experiment were designed by Primer3 software and listed in Supplementary Table S1. The qRT-PCR was carried out using the CFX96 (Bio-Rad, United States) and SYBR Green Premix (Bio-Rad, United States). The PCR cycling condition was as follows: $95^{\circ} \mathrm{C}$ for $1 \mathrm{~min}$, followed by 40 cycles of $95^{\circ} \mathrm{C}$ for $10 \mathrm{~s}$ and $60^{\circ} \mathrm{C}$ for $20 \mathrm{~s}$. In order to verify the primer specificity a melting curve analysis was performed after 40 cycles. The relative expression level was calculated using the $2^{-\Delta \Delta C T}$ method, in which CT indicates cycle threshold.

\section{Statistical Analysis}

All experiments were carried out in triplicate and repeated at least three times. Data shown are illustrative of at least three independent experiments. All the data were statistically analyzed using Student's $t$-test $(P<0.01)$.

\section{RESULT}

\section{Both SbDHN1 and SbDHN2 Were Able to Protect the Enzyme Lactate Dehydrogenase under Oxidative Stress Condition}

The enzyme LDH completely loses its activity when treated with $\mathrm{FeSO}_{4}$ and $\mathrm{H}_{2} \mathrm{O}_{2}$. Transition metal ions in their lower oxidation states like $\mathrm{Fe}^{2+}$ in presence of $\mathrm{H}_{2} \mathrm{O}_{2}$ lead to the production of hydroxyl radical $(\cdot \mathrm{OH})$. Therefore in presence of ROS like $(\mathrm{OH})$ the enzyme LDH losses it activity completely. However, more than $50 \%$ activity was found to be retained by the enzyme when it was incubated in presence of Sorghum dehydrin (SbDHN2) whereas only 30\% activity was retained in presence of SbDHN1 when used at a concentration of $1 \mu \mathrm{g} / \mu \mathrm{l}$ (Figure 1A). The dehydrins were able to protect the LDH activity in a dose dependant manner; where the higher concentration of protein showed greater protective effect, although, after a certain concentration of the dehydrins, this protective effect reached a saturation point (Supplementary Figure S1A). The results were compared with respect to other known protectants like $N$-acetylL-cysteine. Using equimolar amount of the proteins (SbDHN1, SbDHN2, and BSA) for LDH protection assay, SbDHN2 was able to scavenge the hydroxyl radical generated and could act as a better protectant compared to SbDHN1 or BSA under oxidative stress condition (Supplementary Figure S1B). The LDH activity was also affected by the $\mathrm{FeSO}_{4}$ or $\mathrm{H}_{2} \mathrm{O}_{2}$ alone. In presence of higher concentration of $\mathrm{FeSO}_{4}$ or $\mathrm{H}_{2} \mathrm{O}_{2}$, LDH activity was inhibited. For the experimental set up, combination of $0.1 \mathrm{mM}$ $\mathrm{FeSO}_{4}$ and $1 \mathrm{mM} \mathrm{H}_{2} \mathrm{O}_{2}$ was chosen, as these were the minimum concentrations to inhibit the $\mathrm{LDH}$ activity more than $98 \%$. However, using $0.1 \mathrm{mM} \mathrm{FeSO}_{4}$ and $1 \mathrm{mM} \mathrm{H}_{2} \mathrm{O}_{2}$ separately gave $26 \%$ and $32 \%$ inhibition of $\mathrm{LDH}$ activity, respectively (Figures 1B,C). SbDHN2 was also able to quench the effect of $\mathrm{FeSO}_{4}$ or $\mathrm{H}_{2} \mathrm{O}_{2}$ to a greater extent compared to SbDHN1. In presence of $0.1 \mathrm{mM} \mathrm{FeSO}_{4}$ the $\mathrm{LDH}$ can retain up to $74 \%$ of its activity. However, in presence of SbDHN1, SbDHN2 or BSA at a concentration of $1 \mu \mathrm{g} / \mu \mathrm{l}$ the enzyme showed 81,100 , and $75 \%$ of its activity, respectively. On the other hand in presence of $1 \mathrm{mM} \mathrm{H} \mathrm{H}_{2}$, LDH could retain $68 \%$ of its activity, however, in presence of SbDHN1, SbDHN2, or BSA at a concentration of $1 \mu \mathrm{g} / \mu \mathrm{l}, \mathrm{LDH}$ showed approximately 87,92 , and $78 \%$ of its activity, respectively. Our result was further validated by ingel analysis where in the presence of SbDHN2 protein, LDH was protected to a greater extent as compared to SbDHN1 or BSA when equal amount of protein was used in the assay (Supplementary Figure S2).

\section{Analysis of Transgenic Tobacco Plants}

SbDhn1 and SbDhn2 transgenic plants were produced by Agrobacterium-mediated gene transformation method. Both the genes were transformed under the control of CaMV 35S promoter and Nos terminator. Generated transgenic lines were PCR checked for Sbdhn1 or Sbdhn2 and hpt gene. Six PCR positive lines were randomly selected (Line 1, 6, and 10 for Sbdhn1 transformed plants and Line 4, 8, and 14 for Sbdhn2 

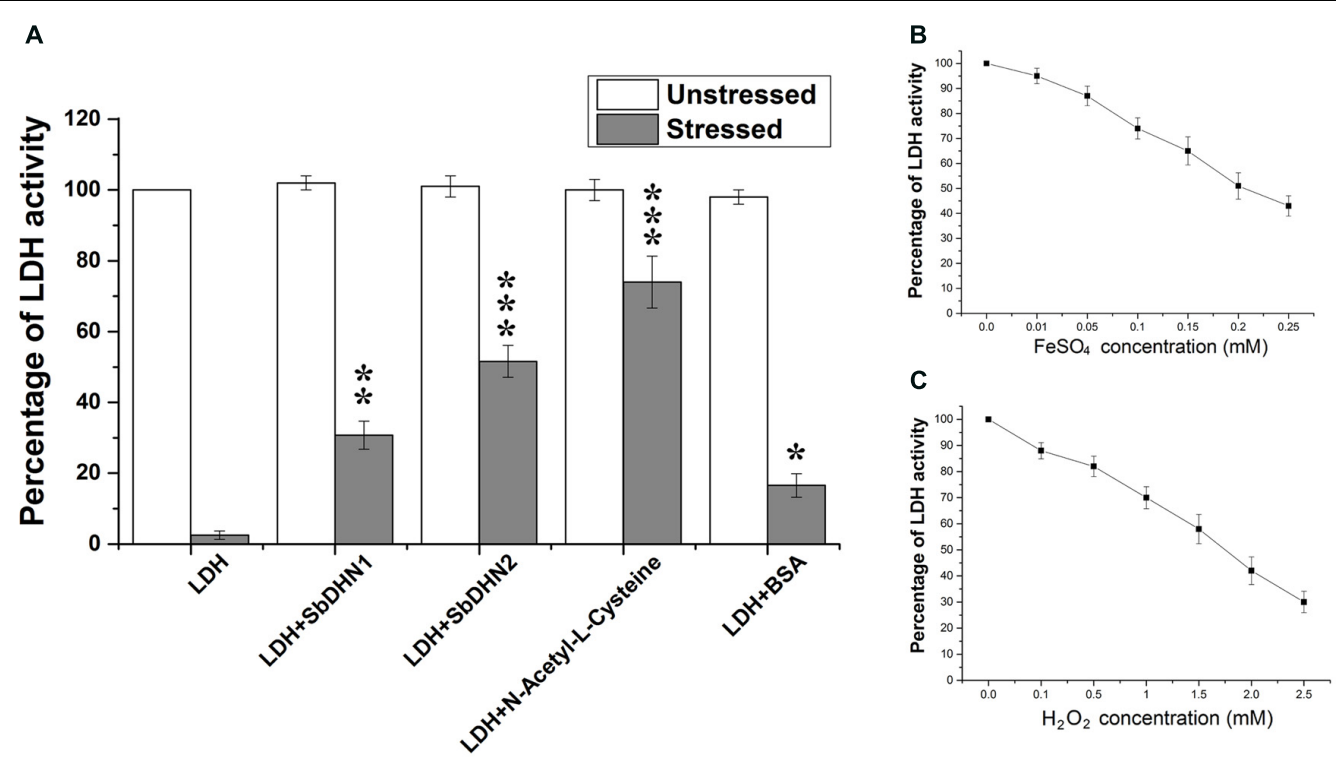

FIGURE 1 | Comparative analysis of protection of LDH activity with two different dehydrins from Sorghum bicolor SbDHN1 and SbDHN2. (A) LDH was subjected to oxidative stress generated by Fenton's reaction in presence and absence of SbDHN1, SbDHN2, N-acetyl-L-cysteine, and BSA. (B) Effect of FeSO ${ }_{4}$ alone on LDH activity in a concentration dependent manner. (C) Effect of $\mathrm{H}_{2} \mathrm{O}_{2}$ alone on $\mathrm{LDH}$ activity in a concentration dependent manner. Error bar represents \pm SEM from at least three replicates. All data were statistically analyzed using Student's $t$-test $\left({ }^{* * *} P<0.0005,{ }^{* *} P<0.005\right.$ and $\left.{ }^{*} P<0.05\right)$. Data shown are illustrations of at least three independent experiments.

transformed plants). Transcript analysis was carried out for the transgenic NT and VT plants. The SbDhn1 and SbDhn2 transformed plants were positive for both $h p t$ and dehydrin genes, respectively. However, the empty vector transformed lines showed amplification for $h p t$ gene only. The NT tobacco plants did not show any amplification for either dehydrins or $h p t$ genes (Supplementary Figure S3).

\section{Transgenic Tobacco Plants Overexpressing Dehydrin Genes Showed Better Protection under Oxidative Stress Conditions}

Leaf discs from NT, VT and transgenic lines over-expressing Sbdhn1 and Sbdhn2 genes were placed on half MS medium supplemented with $20 \mu \mathrm{M}$ MV under continuous illumination for 5 days. Leaf disc from transformed lines over-expressing dehydrin genes showed the better tolerance as compared to NT or VT transformed plants under the stress situation. The NT and VT transformed leaf discs turned pale yellow in color. The leaf discs from SbDhn1 and SbDhn2 transformed plants showed better protection and remained green even after 5 days of MV treatment (Supplementary Figure S4). To validate this observation further, whole plant assay was performed where plants were placed on MS media supplemented with $50 \mu \mathrm{M}$ MV. The transgenic lines expressing dehydrin genes showed better phenotypic expression compared to NT or VT plants (Figure 2) after 5 days of stress treatment. Proline is an important component of cell wall protein which protects membrane integrity and photosynthetic apparatus. (Rai et al., 2012; Ravikumar et al., 2014; Szabados and Savoure, 2010). The proline content increased significantly in transgenic lines overexpressing dehydrin genes. The proline content increased considerably in NT or VT tobacco plants when subjected to MV treatment as opposed to unstressed plants. The level of proline was more in SbDhn2 plants as compared to SbDhn1 plants when subjected to MV treatment. The level of proline accumulation was also higher when the plants were subjected to larger duration of stress treatment (Figure 3A). The MDA content increased considerably in the NT or VT plants as compared to that of transgenic lines. The MDA content increased in all the experimental setups under stress treatment when compared to unstressed control plants. Moreover the amount of MDA content increased with the duration of stress treatment (Figure 3B). Leaf chlorophyll content directly impacts the photosynthetic rate of plants (Ravikumar et al., 2014). ROS generated through the osmotic and oxidative stresses have detrimental effects on both the photosynthetic machinery as well as on the total chlorophyll content of the leaves. The chlorophyll content was also higher in plants over-expressing dehydrin genes, as compared to NT and VT plants when treated with MV for 3 and 5 days (Figure 3C). Under the stressed condition, the soluble sugar content present in the transformed plants over-expressing dehydrin genes was much higher as compared to NT or VT plants (Figure 3D).

\section{Photosynthetic Efficiency Analysis Showed Better Protection of the Over-expressed Dehydrin Lines}

The non-transformed plants which were kept under normal culture conditions showed fully functional electron transport 

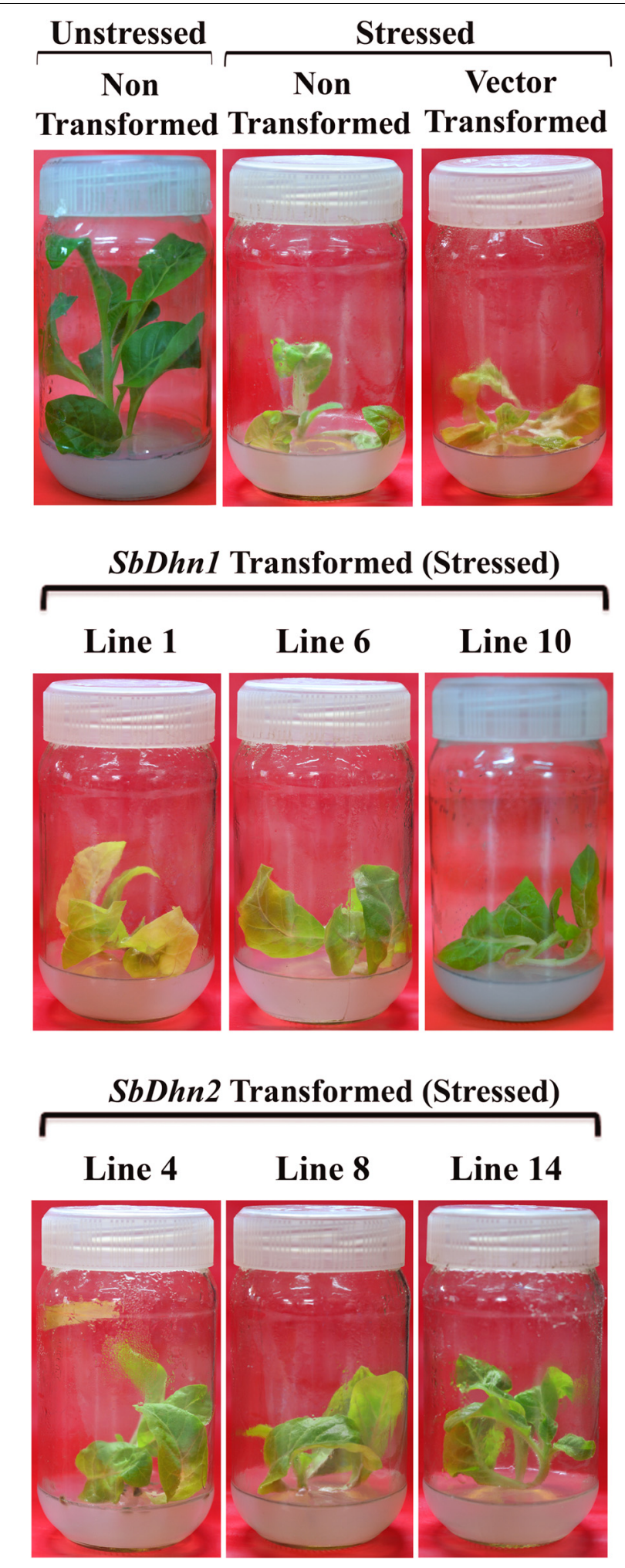

FIGURE 2 | The transgenic tobacco lines (SbDhn1 and SbDhn2) along with NT and VT plants grown in MS medium supplemented with $50 \mu \mathrm{M} \mathrm{MV}$. NT tobacco plants grown under culture condition served as a control in this experiment. Transgenic lines showing better growth compared to NT and VT plants. chain as shown in Figure 4. However, after exposure to MV, the transformed plants over-expressing dehydrin genes showed a significantly higher level of photosynthetic efficiency than NT or VT plants as shown in Figure 4. The electron transport chain showed blocked reaction center in case of NT or VT plants while transgenic lines over-expressing dehydrin genes showed fully functional reactive center comparable to that of the unstressed plant even under oxidative stress condition.

\section{Dehydrins Protects the Photosynthetic Apparatus against Oxidative Damage}

In order to analyze the effect of MV treatment on photosynthetic electron transport we isolated intact chloroplasts and subjected them to MV in presence or absence of dehydrins (SbDHN1 and SbDHN2) and kept under continuous illumination. MV acts as a terminal electron acceptor and generates superoxide radicals in presence of oxygen. Addition of $\mathrm{MnCl}_{2}$ which is a known scavenger of superoxide radicals prior to addition of $\mathrm{MV}$ and its incubation in presence of light showed reduction of DCPIP (data not shown). However, when only intact chloroplasts were incubated with MV in presence of light it showed little reduction of DCPIP as the superoxide radicals generated in the process might have disrupted the electron transport chain considerably. High amount of ROS generated leads to membrane rupture. BSA was used as a control in this experiment. The results showed that the dehydrins were able to render protection to a better extent as compared to BSA (Figure 5A). While the protection activity was better for SbDHN2, but SbDHN1 also provided a fair amount of protection as compared to BSA. Similar result was obtained when chloroplasts isolated from transgenic plants were subjected to MV treatment (Figure 5B). The membrane association property of dehydrin might be one explanation how dehydrin protects the chloroplast membrane and subsequently the electron transport chain.

\section{Scavenging of Superoxide Radicals Impart Protection to Transgenic Plants}

Reactive oxygen species like superoxide radicals were generated as a result of oxidative stress. DHE was used as a probe for in situ localization of the superoxide radical generated under oxidative stress treatment. DHE produces a blue fluorescence until oxidized to ethidium. The superoxide radicals generated in the isolated protoplasts from NT, VT and transgenic lines over expressing dehydrin gene(s) after treatment with $10 \mathrm{mM}$ MV were clearly visible under fluorescence microscope as a blue fluorescence. The level of super oxide generation was very high in protoplast isolated from NT and VT plants as compared to $S b D h n 1$ and SbDhn2 transgenic plants (Figure 6A). The occurrence of the dehydrin proteins in the cytoplasm might scavenge the superoxide radicals generated during oxidative stress.

Similar result was obtained when the whole plants were also treated with MV and the leaves were collected after 5 days of stress treatment. The superoxide radicals generated in NT plants under normal growth conditions was lower as compared to MV treated plants. The transformed plants over-expressing dehydrin 

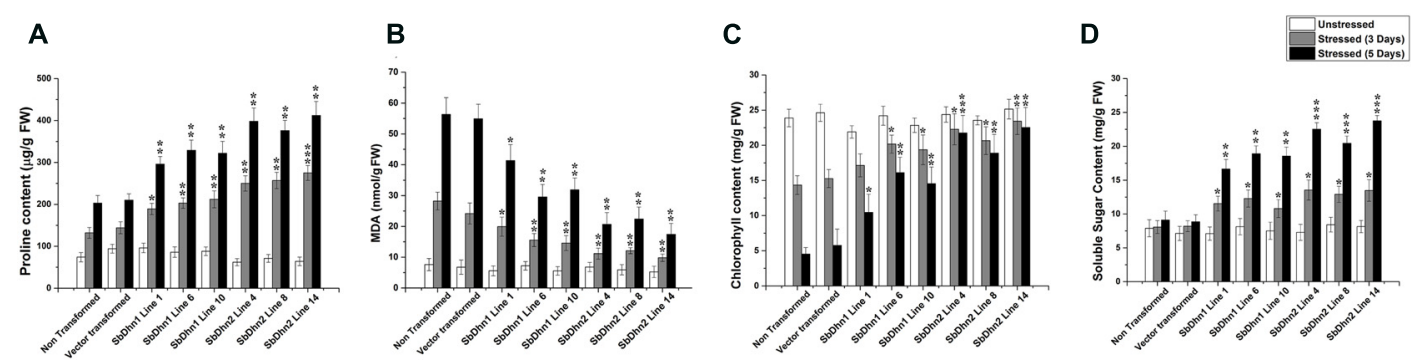

FIGURE 3 | Measurements of different physiological parameters of transgenic tobacco plants (SbDhn1 and SbDhn2) along with NT and VT plants after oxidative stress treatment induced by $50 \mu \mathrm{M}$ of MV in MS medium. All the parameters were collected at 0 day, 3 days, and 5 days of stress treatment. (A) Proline content, (B) MDA content, (C) chlorophyll content, and (D) soluble sugar content. Error bar represents \pm SEM from at least three experimental replicates. All data were statistically analyzed against stressed NT plants using Student's $t$-test ( ${ }^{* *} P<0.0005,{ }^{* *} P<0.005$, and $\left.{ }^{*} P<0.05\right)$. Data shown are illustrative of at least three independent experiments.

genes showed a very low level of blue fluorescence in case of $S b D h n 1$ over-expressed plants when subjected to MV treatment. However, the blue fluorescence was not detected in SbDhn2 transformed plants indicating the superoxide radicals generated was even less in plants transformed with SbDhn2 (Figure 6B). Similar data was obtained in fluorescence spectrometer analysis; the relative fluorescence was much higher in the NT and VT plants than transgenic line after oxidative stress treatments (Figure 6C).

\section{Transformed Line Overexpressing Dehydrin Genes Showed Low Level of $\mathrm{H}_{2} \mathrm{O}_{2}$}

The low level of superoxide radicals generated in transgenic lines implies that the level of $\mathrm{H}_{2} \mathrm{O}_{2}$ formed should also be less in the transgenic plants. After the stress treatment with $\mathrm{MV}, \mathrm{H}_{2} \mathrm{O}_{2}$ accumulation in NT and VT plants was found to be higher, with respect to the dehydrin overexpressing transgenic plants. DAB stained leaves after subsequent removal of chlorophyll showed brown patches of $\mathrm{H}_{2} \mathrm{O}_{2}$ accumulation in the leaf tissues of NT and VT plants. The SbDhn2 plants showed lower level of $\mathrm{H}_{2} \mathrm{O}_{2}$ accumulation even compared to $S b D h n 1$ plants (Figure 7).

\section{The Low Level of ROS in Plants Over-expressing Dehydrin Genes Positively Correlates with an Increase in Enzymatic Activity}

The low level of ROS generated in transgenic lines implies that the level of the ROS scavenging enzymes will also be increased. In order to validate this, we determined the enzymatic activity for SOD, CAT, POX, and APX in NT and transgenic lines following treatment with $50 \mu \mathrm{M}$ of $\mathrm{MV}$ at an interval of 0 day (unstressed), 3 days, and 5 days. The activity levels of SOD, POX, and APX increased significantly in transgenic lines over-expressing dehydrin genes as compared to NT or VT plants after the stress treatment (Figures 8A-C). However, the CAT activity showed little change compared to other ROS scavenging enzymes. The only significant change was observed in case of SbDhn2 over-expressing line after 5 days of stress treatment (Figure 8D). Though, the enzyme activities for all the enzymes studied here increased with the duration of the stress treatment in all the experimental lines when subjected to MV treatment, the activity was higher for transformed plants over-expressing dehydrin genes (both Sbdhn1 and Sbdhn2). The qRT-PCR analysis also showed an upregulation of all the enzymes after stress treatment compared to unstressed control. However, the transcript level of the enzymes studied here (SOD, POX, APX, and CAT genes) were higher in the transgenic lines compared to that of NT and VT plants after MV-induced oxidative stress treatment (Supplementary Figure S5).

\section{DISCUSSION}

Generation of ROS during oxidative conditions leads to damaging effect to the membranes and biomolecules. ROS plays an important role in signaling system in plants and controls processes like growth and development. It acts as a signal in both biotic and abiotic environmental cues (Apel and Hirt, 2004). The ROS includes free radicals like $\mathrm{O}_{2}^{-}$, $\mathrm{OH}^{\cdot}$ and non-radicals like $\mathrm{H}_{2} \mathrm{O}_{2}$ and ${ }^{1} \mathrm{O}_{2}$. Although in low concentration it can act as a signaling molecule, an increased level of this can induce oxidative damage. The delicate balance between production and mitigation of ROS, therefore, remains exceedingly important. The hydroxyl radicals are more reactive compared to the superoxides and $\mathrm{H}_{2} \mathrm{O}_{2}$, thereby readily attacking the lipids, nucleic acids, and proteins at, or close to, the site of their formation (Halliwell and Gutteridge, 1990; Asada, 1994). Therefore, protection towards these highly reactive hydroxyl radicals can be achieved by a mechanism that can prevent its formation. But once produced, the protection depends entirely on the presence of radical scavengers and antioxidants in the close vicinity. The hydroxyl radicals generated in vivo originate mainly from the decomposition of $\mathrm{H}_{2} \mathrm{O}_{2}$, in presence of metal ions such as $\mathrm{Fe}^{2+}$ and $\mathrm{Cu}^{2+}$ where superoxide radicals react with $\mathrm{Fe}^{3+}$ to form $\mathrm{Fe}^{2+}$ and $\mathrm{O}_{2}$ in the process (Asada, 1994; Allen, 1995).

$$
\mathrm{H}_{2} \mathrm{O}_{2}+\mathrm{O}_{2}^{--} \rightarrow \mathrm{OH}^{-}+\mathrm{O}_{2}+\mathrm{OH}
$$



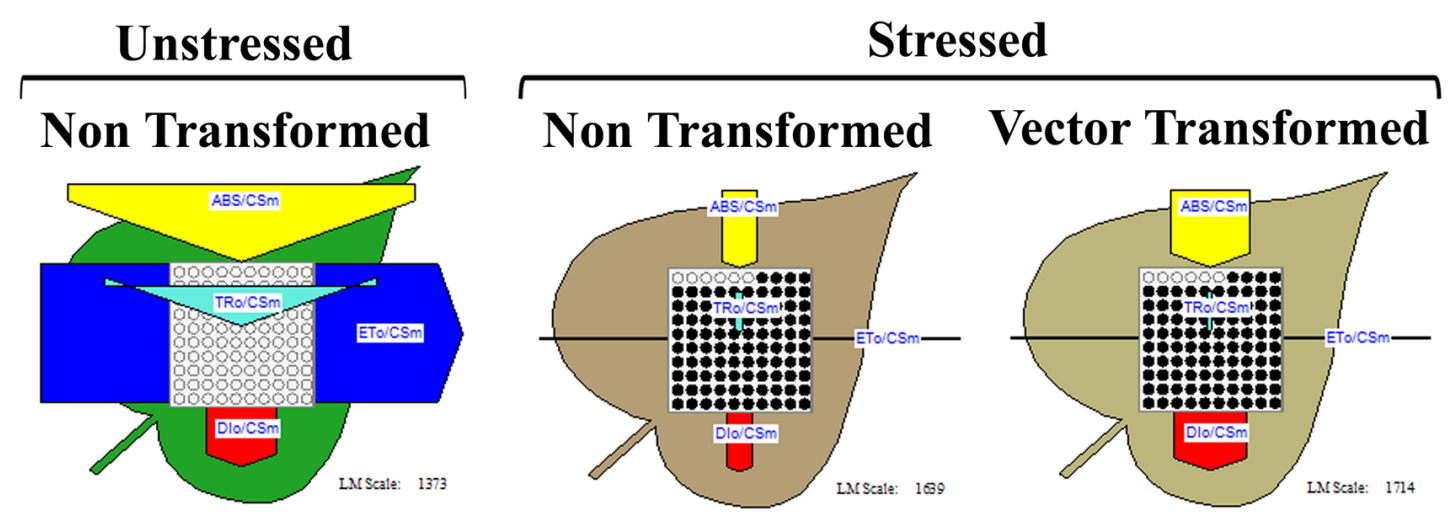

\section{Stressed}

SbDhn1 Transformed (Stressed)

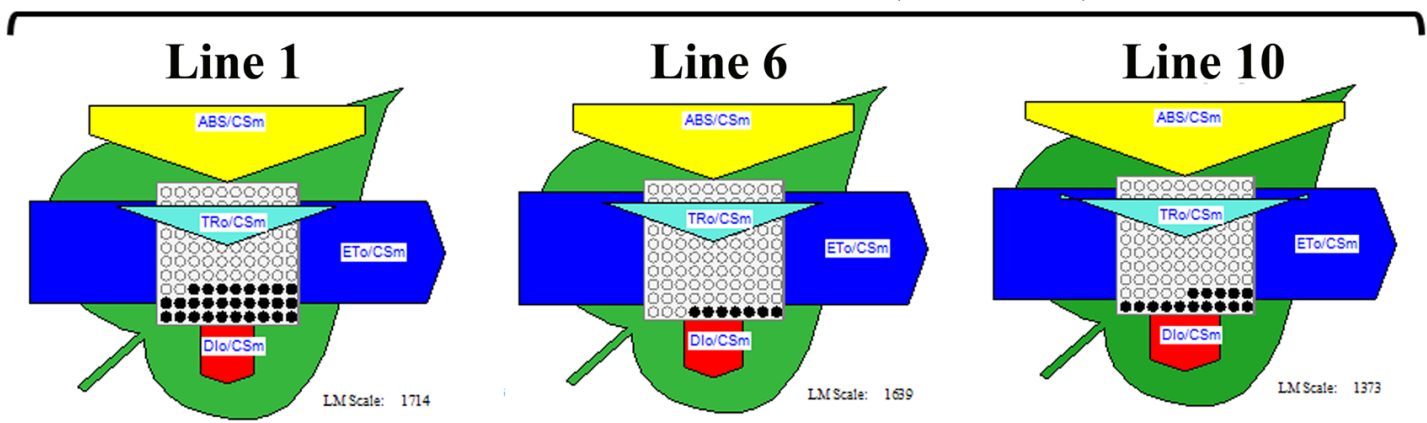

SbDhn2 Transformed (Stressed)

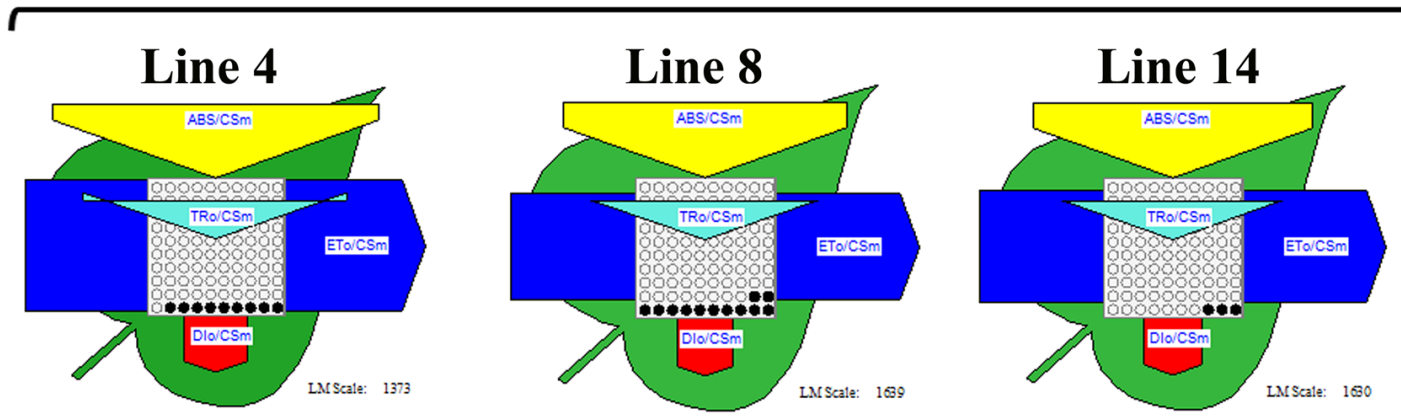

FIGURE 4 | Analysis of photosynthetic efficiency of the NT, VT and transgenic lines over-expressing dehydrin gene(s) (SbDhn1 and SbDhn2) after oxidative stress treatment by $50 \mu \mathrm{M}$ MV for 5 days. Unstressed NT plants grown under normal growth condition served as a control in this experiment. Phenomenological yield models per exited cross-section under oxidative stress; yellow triangle, absorption maxima per excited cross-section (ABS/CS $m$ ); blue pipe, electron transport per excited cross-section $\left(\mathrm{ET}_{0} / \mathrm{CS}_{m}\right)$; green triangle, trapped energy per excited cross-section $\left(\mathrm{TR}_{0} / \mathrm{CS}_{m}\right)$; red block, dissipation maxima per excited cross-section $\left(\mathrm{Dl}_{0} / \mathrm{CS}_{m}\right)$; empty circles, active reaction centers; filled circles, inactive reaction centers.

The generation of the highly reactive hydroxyl radicals depend on the superoxide radicals, $\mathrm{H}_{2} \mathrm{O}_{2}$ and transition metal ions. Scavenging any or all of these components responsible for hydroxyl radical generation will inhibit its formation. In this report, we provided direct evidence to show the protective role of dehydrins in retaining $\mathrm{LDH}$ activity in presence of $\mathrm{H}_{2} \mathrm{O}_{2}$ and $\mathrm{Fe}^{2+}$. The better performance of SbDHN2 compared to the SbDHN1 could be attributed to the fact that SbDHN2 could sequester metal ions owing to a large number of histidine residues present in the amino acid sequence as has been reported earlier by Halder et al. (2016) (Supplementary Table S2). Low level of protection of LDH activity was also observed when BSA was used as a protein control, suggesting that the amino acids and peptide bonds provide a fair amount of protection of $\mathrm{LDH}$ activity under oxidative stress condition.

In order to determine if dehydrin can scavenge the free radicals and impart protection against the highly reactive hydroxyl radicals in vivo, we transformed the wild-type tobacco 

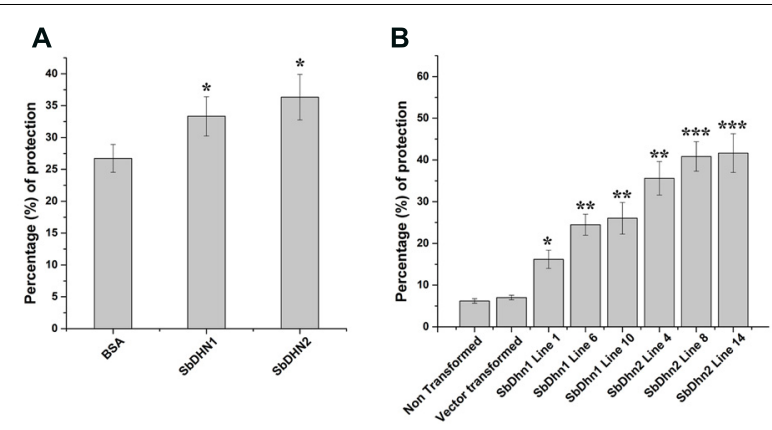

FIGURE 5 | Effect of MV treatment on photosynthetic electron transport in intact chloroplast. (A) Percentage of protection exhibited by externally supplied dehydrin (SbDHN1 and SbDHN2) or BSA on photosynthetic electron transport in intact chloroplast in presence of MV. (B) Effect of MV treatment on photosynthetic electron transport in intact chloroplast isolated from transgenic tobacco plants (SbDhn1 and SbDhn2) along with NT and VT plants. Error bar represents \pm SEM from at least three experimental replicates. All data were statistically analyzed using Student's $t$-test $\left({ }^{* * *} P<0.0005\right.$, ${ }^{* *} P<0.005$, and $\left.{ }^{*} P<0.05\right)$. Data shown are illustrative of at least three independent experiments.

plants with dehydrin gene(s) from Sorghum. The components for generation of hydroxyl radicals were abundant in the chloroplasts because superoxide radicals and $\mathrm{H}_{2} \mathrm{O}_{2}$ are produced in the Mehler reaction of PSI. The generation of hydroxyl radicals lead to damaging conditions for different cellular components by way of LPO thereby leading to disruption of membranes and damaging other biomolecules. Since no single enzymatic system is available for destroying this most reactive radical, therefore excess accumulation of $\mathrm{OH}^{\cdot}$ leads to cellular death (Pinto et al., 2003).

One of the primary components for generation of hydroxyl radical is the superoxide radicals; therefore scavenging off these ROS can, in turn inhibit the production of hydroxyl radical. The MV treatment of intact chloroplasts isolated from NT, VT and transgenic lines overexpressing dehydrin genes was carried out. MV acts as a terminal electron acceptor and subsequently gets oxidized generating superoxide radicals. The increased superoxide radicals can lead to membrane damage thus ultimately inhibiting the electron transport chain. The membrane association property of dehydrin provides a certain level of protection to the isolated chloroplast. The occurrence of $\mathrm{K}$-segment in the dehydrin renders protection against oxidative damage as reported earlier (Liu et al., 2017) possibly by "shielding effect." Additionally, the number and composition of amino acids present in dehydrin might also play an additive role in such protection as large number of histidine residues could sequester the transition metal ions making them unavailable for Fenton reaction. The shielding effect exhibited by dehydrins might be one explanation for such protection. Our results proved beyond doubt that the level of superoxides generated in transgenic lines were significantly lower as compared to NT or VT plants subjected to same stress treatment. These results were further substantiated by the presence of low level of superoxides in the protoplasts isolated from transgenic plants compared with NT and VT plants as evident by the fluorescence level observed with $\mathrm{DHE}$ as a probe. The intracellular superoxide radical generation
A

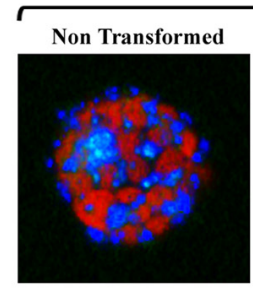

B

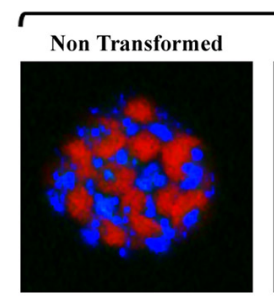

Stressed
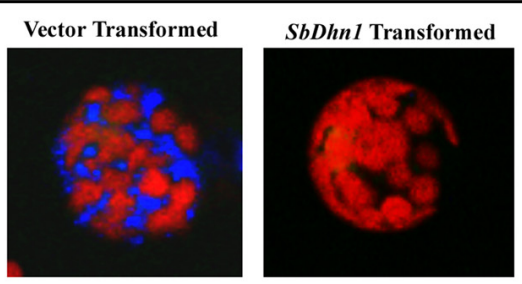

Stressed

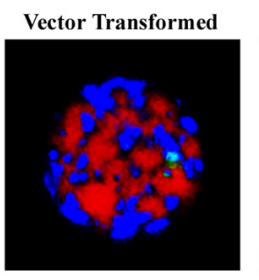

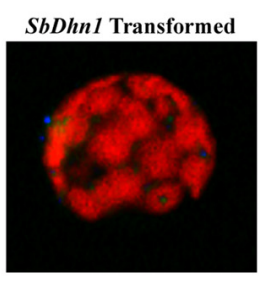

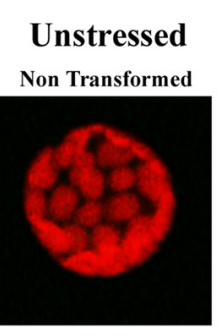

C
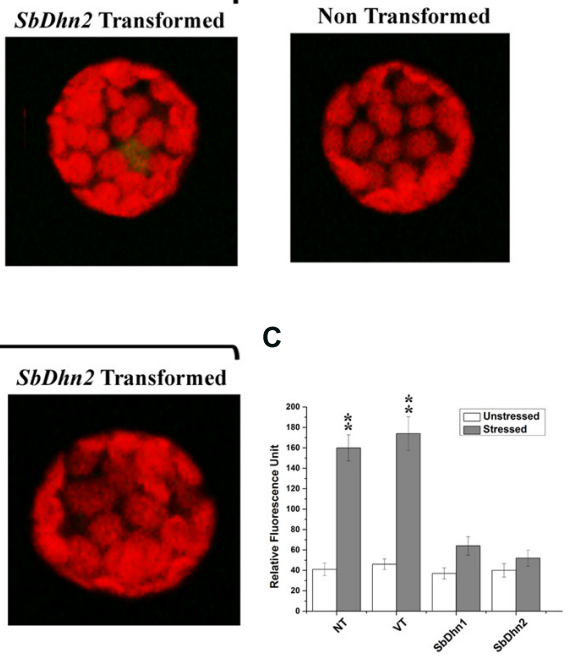

FIGURE 6 | Fluorescence microscope images of isolated protoplast from tobacco plants stained with DHE (A) Protoplast isolated from of NT, VT, and transgenic lines over expressing dehydrin genes (SbDhn1 and SbDhn2) and then subjected to MV treatment followed by staining with DHE (B) Intact protoplast was isolated from NT, VT and transgenic lines over expressing dehydrin genes (SbDhn1 and SbDhn2) subjected to $50 \mu \mathrm{M}$ MV for 5 days. In both the cases protoplast isolated from NT plants without any stress treatment served as control. (C) The relative fluorescence obtained after disruption of the intact protoplast isolated from NT, VT and transgenic lines (SbDhn1 and SbDhn2) subjected to $0 \mu \mathrm{M}$ (unstressed) and $50 \mu \mathrm{M}$ (stressed) MV for 5 days and stained with DHE. Error bar represents \pm SEM from at least three experimental replicates. All data were statistically analyzed using Student's $t$-test ${ }^{* *} P<0.005$ and $\left.* P<0.05\right)$. Data shown are illustrative of at least three independent experiments. 


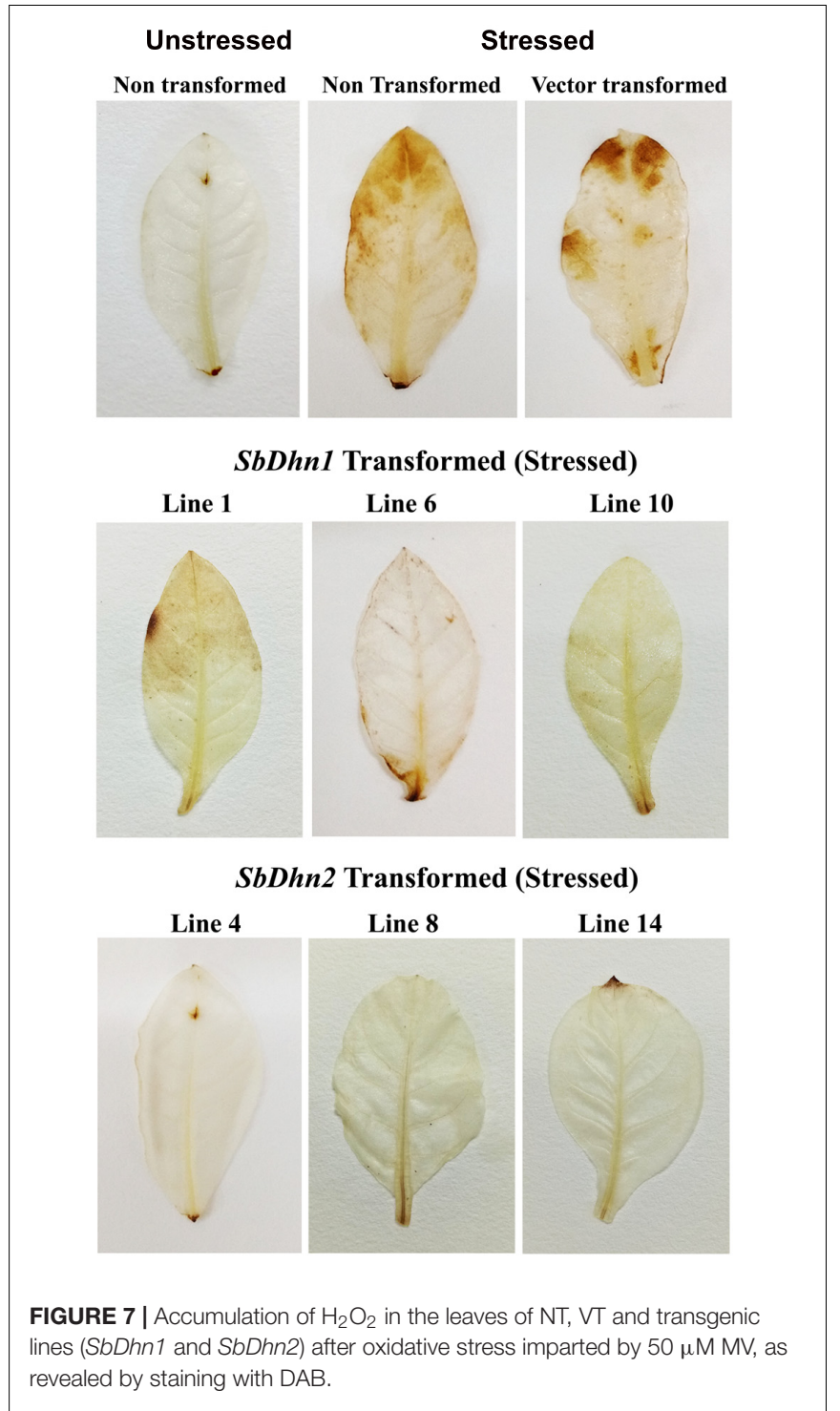

was detected with DHE when excited at $396 \mathrm{~nm}$ allowing more selective imaging of the hydroxylated products produced by superoxide radicals. The fluorescence increased in NT tobacco plants when treated with MV that generates superoxide radicals under illuminated condition. However, the fluorescence intensity generated in over-expressing dehydrin lines was significantly lower as compared with NT or VT lines upon treatment with MV.

An increase in the free proline content was also evident in transgenic lines over-expressing dehydrin genes when compared with WT and VT plants. Apart from acting as osmoprotectant, proline also serves as a scavenger of the free radical thus protecting the biomolecules against oxidative damage (Smirnoff and Cumbes, 1989; Saradhi and Mohanty, 1993; Kaul et al., 2008). The increased proline and other antioxidants at the site of formation of $\mathrm{OH}^{-}$might help to ameliorate the $\mathrm{OH}^{\cdot}$ with high reactivity and low half-life (Signorelli et al., 2013). Though certain amino acids are capable of scavenging the superoxide radicals; however, the large number of proteins present in a cell remains inadequate in scavenging the superoxide radicals which seems to be a property associated with dehydrin. ROS produced in plants under oxidative stress conditions leads to higher MDA content produced due to lipid peroxidation of cell membranes. Our results showed lower levels of MDA in the transgenic lines when compared with WT and VT plants under oxidative stress conditions. The chlorophyll and soluble sugar content were higher in transgenic lines implying that dehydrin over expression results in protection of the photosynthetic machinery in the chloroplast. Furthermore, transgenic plants showed lower levels of $\mathrm{H}_{2} \mathrm{O}_{2}$ when compared with the control plants under stress treatment, as evident by DAB staining of the leaves.

The dismutation of superoxide radicals by SOD also played a significant role. SOD is primarily an important enzyme acting in detoxification reaction which can effectively convert the $\mathrm{O}_{2}$. radicals to $\mathrm{H}_{2} \mathrm{O}_{2}$. The rate of ROS production increases significantly during stress conditions. Detoxification of the increased ROS is effectively carried out by the ROS-scavenging enzymes, namely CAT, SOD, APX, and POXs (Mittler et al., 2004). Additionally, the enhanced activity of the enzyme SOD in the transgenic lines overexpressing dehydrin gene(s) as compared to NT or VT plants might be the result of an indirect protective effect of dehydrin genes. An increase in SOD activity was documented in the leaf tissue obtained from transgenic dehydrin lines as compared to the zero time point measurement under
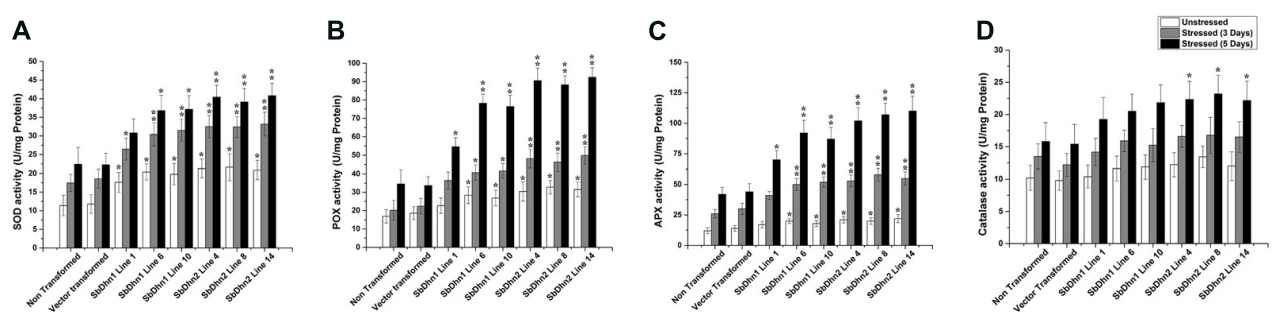

FIGURE 8 | Measurements of antioxidant enzyme activity of transgenic tobacco plants along with NT and VT plants after oxidative stress treatment generated by 50 $\mu \mathrm{M}$ of MV in MS medium. Enzyme activities were measured at 0 day, 3 days, and 5 days of stress treatment. (A) SOD, (B) POX, (C) APX, and (D) CAT. Error bar represents \pm SEM from at least three experimental replicates. All data were statistically analyzed against stressed wild plants using Student's $t$-test $(* * P<0.005$ and $* P<0.05)$. Data shown are illustrative of at least three independent experiments. 
stress treatment. Correspondingly an increase in the activity level of other antioxidant enzymes like APX and POX was also observed. Increase in activity of other antioxidant enzymes suggests that, after dismutation of superoxide radicals into $\mathrm{H}_{2} \mathrm{O}_{2}$ and $\mathrm{O}_{2}$ by SOD, APX reduces $\mathrm{H}_{2} \mathrm{O}_{2}$ into the water in presence of ascorbic acid. Increased APX may constitute a protection mechanism against $\mathrm{H}_{2} \mathrm{O}_{2}$. CAT also plays a significant role in maintaining the ROS homeostasis by catalyzing the decomposition of $\mathrm{H}_{2} \mathrm{O}_{2}$ ( $\mathrm{Du}$ et al., 2008). However, the CAT activity showed only a small level of increase in its activity. This might be due to the fact that CAT activity depends on the increased $\mathrm{H}_{2} \mathrm{O}_{2}$ concentration and a certain threshold level of $\mathrm{H}_{2} \mathrm{O}_{2}$ perhaps is essential for CAT activity. The localized occurrence of CAT in peroxisomes and a very low affinity for $\mathrm{H}_{2} \mathrm{O}_{2}$ might be the reason for its small change in activity level. Our results strongly suggest that functional co-operation between the radical scavenging enzymes remains essential for protection against the ROS generated.

There are substantial evidences documented here that dehydrins can scavenge the superoxide radicals generated thereby increasing the ability to cope with the oxidative damage generated as a result of MV treatment. An increase in ROS scavenging enzymes might function cooperatively with the dehydrins but the actual mechanism how this happens remains unexplained. Scavenging of superoxide radicals and transition metals by SbDHN2 led to a better protection of plants as compared to SbDHN1. Thus we conclude from the evidences documented from in vitro and in vivo experiments that there lies an indirect involvement of dehydrin in protection against hydroxyl radical. Therefore over-expression of dehydrins have resulted in an increased resistance to oxidative damage which is reflected by the better photosynthetic efficiency of the transgenic plants as compared to NT or VT plants. Increase in soluble sugars, radical scavengers, enzymes related to antioxidative pathways, sequestration of transition metal ions all allow for an ROS homeostasis inside the cells.

\section{AUTHOR CONTRIBUTIONS}

All authors have participated sufficiently in the work to take public responsibility for appropriate portions of the content.

\section{REFERENCES}

Ábrahám, E., Hourton-Cabassa, C., Erdei, L., and Szabados, L. (2010). Methods for determination of proline in plants. Methods Mol. Biol. 639, 317-331. doi: 10.1007/978-1-60761-702-0_20

Agarwal, T., Upadhyaya, G., Halder, T., Mukherjee, A., Majumder, A. L., and Ray, S. (2017). Different dehydrins perform separate functions in Physcomitrella patens. Planta 245, 101-118. doi: 10.1007/s00425-0162596-1

Allen, R. D. (1995). Dissection of oxidative stress tolerance using transgenic plants. Plant Physiol. 107, 1049.

Apel, K., and Hirt, H. (2004). Reactive oxygen species: metabolism, oxidative stress, and signal transduction. Annu. Rev. Plant Biol. 55, 373-399. doi: 10.1146/ annurev.arplant.55.031903.141701

Arnon, D. I. (1949). Copper enzyme polyphenoloxides in isolated chloroplast in Beta vulgaris. Plant Physiol. 24, 1-15. doi: 10.1104/pp.24.1.1
No one, other than the authors listed below has contributed substantially to the writing and revising of the manuscript. Contributors who do not meet the criteria for authorship have been listed in the acknowledgment. Study conception and design: SR, TH, and GU; Acquisition of data: TH, GU, CB, AD, and $\mathrm{CC}$; Analysis and interpretation of data: $\mathrm{TH}, \mathrm{GU}, \mathrm{CB}, \mathrm{AD}$, and CC; Drafting of manuscript: SR, TH, and GU; Critical revision: SR.

\section{FUNDING}

This work was supported by grants to SR from the Department of Science and Technology, Government of India (Sanction No. SERB/SR/SO/PS-30/2010). TH thanks the Council of Scientific and Industrial Research, Government of India for Research Fellowship (Sanction No. 09/028(0914)/2013-EMR-I). GU thanks the Department of Science and Technology, Government of India for Research Fellowship (Sanction No. DST/INSPIRE Fellowship/2015/IF150503). CB and CC thank the University Grants Commission, Government of India for Research Fellowship (Sanction No. UGC/134/JR. Fellow 03/02/2015), (UGC/1060/Fellow (Univ.) 22/08/2014), respectively. $\mathrm{AD}$ thanks the Department of Biotechnology, Government of India for Research Fellowship (Sanction No. BT/PR8377/PBD/16/1046/2013).

\section{ACKNOWLEDGMENTS}

We express our whole hearted thank to DST-FIST and UGC CAS for instrumental facilities of Department of Botany, University of Calcutta. We thank Prof. A. N. Lahiri Majumder of Bose Institute for constant support.

\section{SUPPLEMENTARY MATERIAL}

The Supplementary Material for this article can be found online at: https://www.frontiersin.org/articles/10.3389/fpls.2018.00136/ full\#supplementary-material

Asada, K. (1994). "Production and action of active oxygen species in photosynthetic tissues," in Causes of Photooxidative Stress and Amelioration of Defense Systems in Plants, eds C. H. Foyer and P. M. Mullineaux (Boca Raton, FL: CRC Press), 77-104.

Baryla, A., Laborde, C., Montillet, J. L., Triantaphylides, C., and Chagvardieff, P. (2000). Evaluation of lipid peroxidation as a toxicity bioassay for plants exposed to copper. Environ. Pollut. 109, 131-135. doi: 10.1016/S0269-7491(99)00232-8

Bolhar-Nordenkampf, H. R., Long, S. P., Baker, N. R., Oquist, G., Schreiber, U. L. E. G., and Lechner, E. G. (1989). Chlorophyll fluorescence as a probe of the photosynthetic competence of leaves in the field: a review of current instrumentation. Funct. Ecol. 3, 497-514. doi: 10.2307/ 2389624

Cakmak, I., and Horst, W. J. (1991). Effect of aluminium on lipid peroxidation, superoxide dismutase, catalase, and peroxidase activities in root tips of soybean (Glycine max). Physiol. Plant 83, 463-468. doi: 10.1111/j.1399-3054.1991. tb00121.x 
Close, T. J. (1997). Dehydrins: a commonalty in the response of plants to dehydration and low temperature. Plant Physiol. 100, 291-296. doi: 10.1111/ j.1399-3054.1997.tb04785.x

Danyluk, J., Perron, A., Houde, M., Limin, A., Fowler, B., Benhamou, N., et al. (1998). Accumulation of an acidic dehydrin in the vicinity of the plasma membrane during cold acclimation of wheat. Plant Cell 10, 623-638. doi: 10 . $1105 /$ tpc.10.4.623

Daudi, A., and O'Brien, J. A. (2012). Detection of hydrogen peroxide by DAB staining in Arabidopsis leaves. Plant Cell 2:e263. doi: 10.21769/BioProtoc.263

Du, Y. Y., Wang, P. C., Chen, J., and Song, C. P. (2008). Comprehensive functional analysis of the catalase gene family in Arabidopsis thaliana. J. Integr. Plant Biol. 50, 1318-1326. doi: 10.1111/j.1744-7909.2008.00741.x

Eriksson, S. K., Kutzer, M., Procek, J., Gröbner, G., and Harryson, P. (2011). Tunable membrane binding of the intrinsically disordered dehydrin Lti30, a cold-induced plant stress protein. Plant Cell 23, 2391-2404. doi: 10.1105/tpc. 111.085183

Force, L., Critchley, C., and van Rensen, J. J. (2003). New fluorescence parameters for monitoring photosynthesis in plants. Photosynth. Res. 78, 17-33.

Foyer, C. H., and Mullineaux, P. M. (1994). Causes of Photooxidative Stress and Amelioration of Defense Systems in Plants. Boca Raton, FL: CRC press.

Genaro-Mattos, T. C., Maurício, ÂQ., Rettori, D., Alonso, A., and HermesLima, M. (2015). Antioxidant activity of caffeic acid against iron-induced free radical generation-a chemical approach. PLOS ONE 10:e0129963. doi: 10.1371/ journal.pone.0129963

Halder, T., Agarwal, T., and Ray, S. (2016). Isolation, cloning, and characterization of a novel Sorghum dehydrin (SbDhn2) protein. Protoplasma 253, 1475-1488. doi: 10.1007/s00709-015-0901-7

Halder, T., Upadhyaya, G., and Ray, S. (2017). YSK 2 type dehydrin (SbDhn1) from Sorghum bicolor showed improved protection under high temperature and osmotic stress condition. Front. Plant Sci. 8:918. doi: 10.3389/fpls.2017.00918

Halliwell, B., and Gutteridge, J. M. (1990). Role of free radicals and catalytic metal ions in human disease: an overview. Methods Enzymol. 186, 1-85. doi: 10.1016/0076-6879(90)86093-B

Hara, M., Fujinaga, M., and Kuboi, T. (2004). Radical scavenging activity and oxidative modification of citrus dehydrin. Plant Physiol. Biochem. 42, 657-662. doi: 10.1016/j.plaphy.2004.06.004

Hara, M., Fujinaga, M., and Kuboi, T. (2005). Metal binding by citrus dehydrin with histidine-rich domains. J. Exp. Bot. 56, 2695-2703. doi: 10.1093/jxb/eri262

Hara, M., Kondo, M., and Kato, T. (2013). A KS-type dehydrin and its related domains reduce $\mathrm{Cu}$-promoted radical generation and the histidine residues contribute to the radical-reducing activities. J. Exp. Bot. 64, 1615-1624. doi: $10.1093 /$ jxb/ert016

Hara, M., Terashima, S., Fukaya, T., and Kuboi, T. (2003). Enhancement of cold tolerance and inhibition of lipid peroxidation by citrus dehydrin in transgenic tobacco. Planta 217, 290-298. doi: 10.1007/s00425-003-0986-7

Hara, M., Terashima, S., and Kuboi, T. (2001). Characterization and cryoprotective activity of cold-responsive dehydrin from Citrus unshiu. J. Plant Physiol. 158, 1333-1339. doi: 10.1078/0176-1617-00600

Horsch, R. B., Fry, J. E., Hoffmann, N. L., Eichholtz, D., Rogers, S. G., and Fraley, R. T. (1985). A simple and general method for transferring genes into plants. Science 227, 1229-1231. doi: 10.1126/science.227.4691.1229

Irigoyen, J. J., Einerich, D. W., and Sánchez-Díaz, M. (1992). Water stress induced changes in concentrations of proline and total soluble sugars in nodulated alfalfa (Medicago sativd) plants. Physiol. Plant 84, 55-60. doi: 10.1111/j.13993054.1992.tb08764.x

Ismail, A. M., Hall, A. E., and Close, T. J. (1999). Purification and partial characterization of a dehydrin involved in chilling tolerance during seedling emergence of cowpea. Plant Physiol. 120, 237-244. doi: 10.1104/pp. 120.1.237

Kaul, S., Sharma, S. S., and Mehta, I. K. (2008). Free radical scavenging potential of L-proline: evidence from in vitro assays. Amino Acids 34, 315-320. doi: 10.1007/s00726-006-0407-x

Koag, M. C., Fenton, R. D., Wilkens, S., and Close, T. J. (2003). The binding of maize DHN1 to lipid vesicles: gain of structure and lipid specificity. Plant Physiol. 131, 309-316. doi: 10.1104/pp.011171

Koag, M. C., Wilkens, S., Fenton, R. D., Resnik, J., Vo, E., and Close, T. J. (2009). The K-segment of maize DHN1 mediates binding to anionic phospholipid vesicles and concomitant structural changes. Plant Physiol. 150, 1503-1514. doi: $10.1104 /$ pp.109.136697

Konrad, Z., and Bar-Zvi, D. (2008). Synergism between the chaperone-like activity of the stress regulated ASR1 protein and the osmolyte glycine-betaine. Planta 227, 1213-1219. doi: 10.1007/s00425-008-0693-5

Liang, J. G., Tao, R. X., Hao, Z. N., Wang, L. P., and Zhang, X. (2011). Induction of resistance in cucumber against seedling damping-off by plant growth-promoting rhizobacteria (PGPR) Bacillus megaterium strain L8. Afr. J. Biotechnol. 10, 6920-6927.

Liu, Y., Wang, L., Zhang, T., Yang, X., and Li, D. (2017). Functional characterization of KS-type dehydrin ZmDHN13 and its related conserved domains under oxidative stress. Sci. Rep. 7:7361. doi: 10.1038/s41598-01707852-y

Malik, C. P., and Singh, M. B. (1980). Plant enzymology and histoenzymology. A text manual. New Delhi: Kalyani Publishers, 59-60.

Mittler, R. (2002). Oxidative stress, antioxidants and stress tolerance. Trends Plant Sci. 7, 405-410. doi: 10.1016/S1360-1385(02)02312-9

Mittler, R., Vanderauwera, S., Gollery, M., and Van Breusegem, F. (2004). Reactive oxygen gene network of plants. Trends Plant Sci. 9, 490-498. doi: 10.1016/j. tplants.2004.08.009

Murashige, T., and Skoog, F. (1962). A revised medium for rapid growth and bioassays with tobacco tissue cultures. Physiol. Plant. 15, 473-497. doi: 10.1111/ j.1399-3054.1962.tb08052.x

Nakano, Y., and Asada, K. (1981). Hydrogen peroxide is scavenged by ascorbatespecific peroxidase in spinach chloroplasts. Plant Cell Physiol. 22, 867-880. doi: 10.1093/oxfordjournals.pcp.a076232

Orozco-Cárdenas, M. L., Narváez-Vásquez, J., and Ryan, C. A. (2001). Hydrogen peroxide acts as a second messenger for the induction of defense genes in tomato plants in response to wounding, systemin, and methyl jasmonate. Plant Cell 13, 179-191. doi: 10.1105/tpc.13.1.179

Pinto, E., Sigaud-kutner, T., Leitao, M. A., Okamoto, O. K., Morse, D., and Colepicolo, P. (2003). Heavy metal-induced oxidative stress in algae. J. Phycol. 39, 1008-1018. doi: 10.1111/j.0022-3646.2003.02-193.x

Rahman, L. N., Chen, L., Nazim, S., Bamm, V. V., Yaish, M. W., Moffatt, B. A., et al. (2010). Interactions of intrinsically disordered Thellungiella salsuginea dehydrins TsDHN-1 and TsDHN-2 with membranes-synergistic effects of lipid composition and temperature on secondary structure. Biochem. Cell Biol. 88, 791-807. doi: 10.1139/O10-026

Rahman, L. N., McKay, F., Giuliani, M., Quirk, A., Moffatt, B. A., Harauz, G., et al. (2013). Interactions of Thellungiella salsuginea dehydrins TsDHN-1 and TsDHN-2 with membranes at cold and ambient temperatures-Surface morphology and single-molecule force measurements show phase separation, and reveal tertiary and quaternary associations. Biochim. Biophys. Acta 1828, 967-980. doi: 10.1016/j.bbamem.2012.11.031

Rai, S., Kumar, N. S., and Singh, H. (2012). A theoretical study on interaction of proline with gold cluster. Bull. Mater. Sci. 35, 291-295. doi: 10.1007/s12034012-0314-6

Ravikumar, G., Manimaran, P., Voleti, S. R., Subrahmanyam, D., Sundaram, R. M., Bansal, K. C., et al. (2014). Stress-inducible expression of AtDREB1A transcription factor greatly improves drought stress tolerance in transgenic indica rice. Transgenic Res. 23, 421-439. doi: 10.1007/s11248-0139776-6

Saradhi, P. P., and Mohanty, P. (1993). Proline in relation to free radical production in seedlings of Brassica juncea raised under sodium chloride stress. Plant Soil $155,497-500$

Shekhawat, U. K., and Ganapathi, T. R. (2013). MusaWRKY71 overexpression in banana plants leads to altered abiotic and biotic stress responses. PLOS ONE 8:e75506. doi: 10.1371/journal.pone.0075506

Signorelli, S., Coitinpo, E. L., Borsani, O., and Monza, J. (2013). Molecular mechanisms for the reaction between $\mathrm{OH}$ radicals and proline: insights on the role as reactive oxygen species scavenger in plant stress. J. Phys. Chem. 118, 37-47. doi: 10.1021/jp407773u

Smirnoff, N., and Cumbes, Q. J. (1989). Hydroxyl radical scavenging activity of compatible solutes. Phytochemistry 28, 1057-1060. doi: 10.1016/0031-9422(89) 80182-7

Soulages, J. L., Kim, K., Arrese, E. L., Walters, C., and Cushman, J. C. (2003). Conformation of a group 2 late embryogenesis abundant protein from soybean. 
Evidence of poly (L-proline)-type II structure. Plant Physiol. 131, 963-975. doi: $10.1104 /$ pp.015891

Szabados, V., and Savoure, A. (2010). Proline: a multifunctional amino acid. Trends Plant Sci. 15, 89-97. doi: 10.1016/j.tplants.2009.11.009

Van Breusegem, F., Slooten, L., Stassart, J. M., Moens, T., Botterman, J., Van Montagu, M., et al. (1999). Overproduction of Arabidopsis thaliana FeSOD confers oxidative stress tolerance to transgenic maize. Plant Cell Physiol. 40, 515-523. doi: 10.1093/oxfordjournals.pcp.a029572

Yang, Y., Sun, X., Yang, S., Li, X., and Yang, Y. (2014). Molecular cloning and characterization of a novel SK3-type dehydrin gene from Stipa purpurea. Biochem. Biophys. Res. Commun. 448, 145-150. doi: 10.1016/j.bbrc.2014. 04.075

Yoo, S. D., Cho, Y. H., and Sheen, J. (2007). Arabidopsis mesophyll protoplasts: a versatile cell system for transient gene expression analysis. Nat. Protoc. 2:1565. doi: 10.1038/nprot.2007.199
Zhang, Y., Li, J., Yu, F., Cong, L., Wang, L., Burkard, G., et al. (2006). Cloning and expression analysis of $\mathrm{SK}_{n}$-type dehydrin gene from bean in response to heavy metals. Mol. Biotechnol. 32, 205-217. doi: 10.1385/MB:32:3:205

Conflict of Interest Statement: The authors declare that the research was conducted in the absence of any commercial or financial relationships that could be construed as a potential conflict of interest.

Copyright (c) 2018 Halder, Upadhyaya, Basak, Das, Chakraborty and Ray. This is an open-access article distributed under the terms of the Creative Commons Attribution License (CC BY). The use, distribution or reproduction in other forums is permitted, provided the original author(s) and the copyright owner are credited and that the original publication in this journal is cited, in accordance with accepted academic practice. No use, distribution or reproduction is permitted which does not comply with these terms. 